\title{
Atopic dermatitis: an expanding therapeutic pipeline for a complex disease
}

\section{Thomas Bieber (10) $1,2,3$}

Abstract | Atopic dermatitis (AD) is a common chronic inflammatory skin disease with a complex pathophysiology that underlies a wide spectrum of clinical phenotypes. AD remains challenging to treat owing to the limited response to available therapies. However, recent advances in understanding of disease mechanisms have led to the discovery of novel potential therapeutic targets and drug candidates. In addition to regulatory approval for the IL-4Ra inhibitor dupilumab, the anti-IL-13 inhibitor tralokinumab and the JAK1/2 inhibitor baricitinib in Europe, there are now more than 70 new compounds in development. This Review assesses the various strategies and novel agents currently being investigated for $A D$ and highlights the potential for a precision medicine approach to enable prevention and more effective long-term control of this complex disease.

Atopic disorders

A group of disorders having in common a genetic tendency to develop IgE-mediated allergic reactions. These are atopic dermatitis, food allergy, allergic rhino-conjunctivitis and allergic asthma.

Rhino-conjunctivitis An atopic disorder of the eyes and nose as the clinical manifestation of an allergic reaction to environmental allergens.

Biologic therapies Therapeutic approach using antibodies or other biological and recombinant products typically directed against pathway-related structures

'Department of Dermatology and Allergy, University Hospital, Bonn, Germany.

${ }^{2}$ Christine Kühne-Center for Allergy Research and Education, Davos, Switzerland.

${ }^{3}$ Davos Biosciences, Davos, Switzerland. e-mail:Thomas.Bieber@ ukbonn.de
Atopic dermatitis (AD) is the most common chronic inflammatory skin disease ${ }^{1,2}$. About $80 \%$ of disease cases typically start in infancy or childhood, with the remainder developing during adulthood. Whereas the point prevalence in children varies from $2.7 \%$ to $20.1 \%$ across countries, it ranges from $2.1 \%$ to $4.9 \%$ in adults ${ }^{3,4}$. The disease displays a high heterogeneity in its natural course and individual trajectories are unpredictable. $\mathrm{AD}$ is characterized by sensitive and dry skin, localized or disseminated eczematous lesions usually accompanied by a severe itching sensation. The heterogeneous clinical phenotype varies by age, severity and ethnic background $^{5}$. AD has a significant impact on the quality of life of the patients and their relatives ${ }^{6}$ and represents an important socio-economic burden with an average yearly total (direct and indirect) cost per patient of $€ 15,000\left(\right.$ REFS $\left.^{7-9}\right)$.

$\mathrm{AD}$ belongs to the spectrum of the atopic disorders, including food allergy, allergic asthma and allergic rhinoconjunctivitis, which are relevant comorbidities ${ }^{10}$. Immunoglobulin E (IgE)-related allergic reactions to environmental allergens represent the common aspect of atopic diseases. Recently, cardiovascular and neuropsychiatric disorders have also been reported to be relevant comorbidities to $\mathrm{AD}$, although the mechanisms underlying these associations remain elusive $\mathrm{e}^{11-13}$.

So far, however, AD has primarily been considered as merely a skin disorder in which local anti-inflammatory therapy of the disease flares should be the first-line approach $^{14,15}$. Such topical therapies include various topical corticosteroids (TCSs), the topical calcineurin inhibitors tacrolimus and pimecrolimus and more recently the phosphodiesterase 4 (PDE4) inhibitor crisaborole. For the more severe forms of $\mathrm{AD}$, besides the use of ultraviolet light, current therapeutic guidelines suggest ciclosporin $\mathrm{A}$, methotrexate, azathioprine and mycophenolate mofetil.

The approvals of the anti-IL-4R a antibody dupilumab (2016, FDA/2017, EMA) and more recently of the small-molecule Janus kinase inhibitor baricitinib (2020, EMA) and the anti-IL-13 antibody tralokinumab (2021, EMA) have provided first-in-class representatives of different therapeutic strategies for the treatment of moderate to severe forms of AD. Dupilumab and tralokinumab are examples of targeted biologic therapies that specifically address a distinct immune pathway and its cytokines or receptors $^{16}$, whereas baricitinib exemplifies a more wide-ranging approach using small molecules ${ }^{17}$ that interact with multiple signal transduction pathways linked to several cytokine receptors and immune pathways. Despite these recent developments, the current therapeutic armamentarium remains very limited and disease management still follows a 'one-size-fits-all' paradigm. In particular, the high incidence of $\mathrm{AD}$ in the paediatric population, the highly fluctuating and unpredictable course of disease and the limited armamentarium of approved drugs with an adequate benefitrisk ratio represent major challenges in the field. To address this, a better understanding of the mechanisms that underlie the epidermal barrier dysfunction and the sequence of immune responses that underlie the chronic inflammatory reaction is needed, which would ideally 


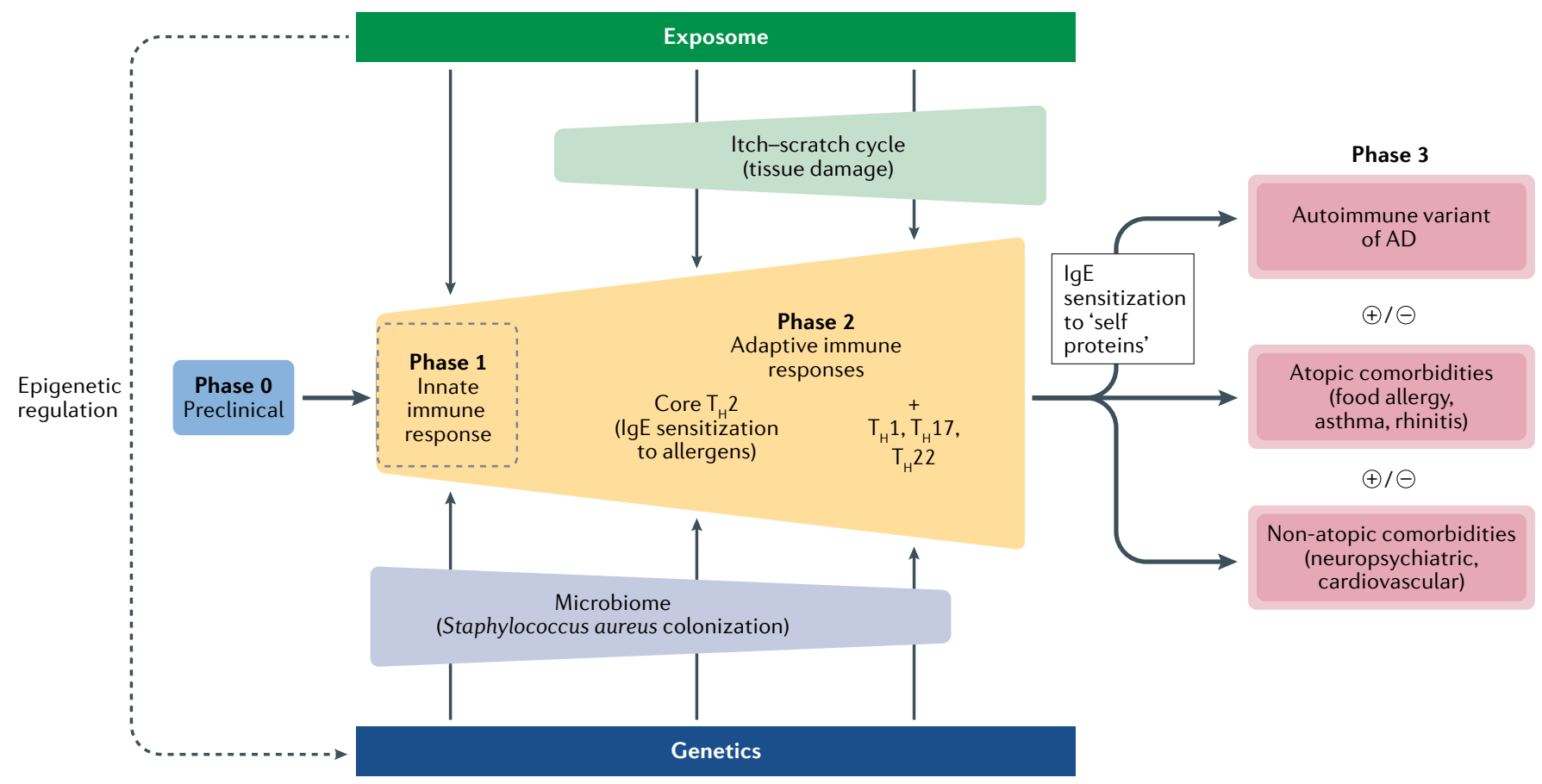

Fig. 1 | A multidimensional model of atopic dermatitis. A high-level schematic view of the complex interactions that underlie the immunological heterogeneity of atopic dermatitis (AD). This multidimensional disease model generates an 'immunological march', which can schematically and tentatively be dissected in several, potentially overlapping phases: first, an asymptomatic preclinical phase (phase 0 ); second, activation of skin innate immunity (phase 1), rapidly followed by activation of the adaptive immune response (phase 2 ) starting with a core Thelper $2\left(T_{H} 2\right)$ response accompanied by lgE sensitization to environmental allergens, and a widening of the adaptive immunity with $T_{H} 1, T_{H} 17$ and $T_{H} 22$ responses. This widening of the immune response paves the way for the development of atopic and non-atopic comorbidities (phase 3). Each putative phase offers opportunities for preventive and targeted therapeutic intervention, including disease modification. In this scenario, the composition of the skin microbiome and the itch-scratch cycle potentially have a crucial role in directing the adaptive immunity and the development of sensitization to self proteins, atopic and non-atopic comorbidities.

translate into optimized long-term, disease-modifying management of this chronic disorder.

In the past two decades, significant progress has been made in our understanding of the complex phenotype and mechanisms that underlie $\mathrm{AD}^{18}$, offering multiple new potential targets for pharmacological intervention ${ }^{19}$. More than 70 new compounds are in development and this Review will assess those that are being investigated in clinical trials. The variety of targets and strategies offers significant potential for a precision medicine approach to the management of $\mathrm{AD}$.

\section{Exposomal factors}

A highly heterogeneous group of exogenous and environmental factors that influence the human body and immune system.

Skin microbiome

The sum of all bacteria colonizing the surface or deep structures of the skin.

Immunological march Sequence of physiological or pathophysiological events leading to different types of immune response.

the epidermal barrier ${ }^{27,28}$; and fourth, the immune and inflammatory responses ${ }^{18}$, which cause, fifth, the itch-scratch cycle ${ }^{29}$. These interactions develop on a particular genetic ${ }^{30}$ and yet-to-be explored epigenetic background. This is accompanied by a dynamic of the immune response ('immunological march') with a potential systemic impact of the inflammatory reaction, that is, secondary involvement of other organs. The main cellular and soluble components involved in the pathophysiology of $\mathrm{AD}$ represent the key targets of current efforts in pharmacological intervention (FIG. 2). Moreover, the complexity of the immune pathways that operate in $\mathrm{AD}$ offers the opportunity to explore the potential of bispecific or trispecific antibodies.

For practical purposes, disease severity remains the basis for the treatment algorithm in the current guidelines $\mathrm{s}^{31-35}$. The spectrum of $\mathrm{AD}$ has been divided into mild, moderate and severe forms, and cut-off points using the scoring tools for the assessment of severity and efficacy as well as patient-reported outcomes (see BOX 2) have been defined ${ }^{36,37}$. Depending on the individual patient's natural and unpredictable course of the disorder, its management has two main goals: the rapid and efficacious treatment of acute flares and the far more challenging control of the disease in the long term. Thus, besides efficacy, the long-term safety profile is a key aspect of any new compound in a clinical development programme.

\section{Modulating the skin microbiome}

Several distinct strategies to restore or modulate the composition of the skin microbiome have been proposed ${ }^{38-40}$. Microbiome transplantation and bacterial replacement 
Bacteriotherapy

Therapeutic approaches using living bacteria to influence the microbiome composition.

Pruritus

Sensation of itching generated at the level of sensory neurons and leading to scratching as a mechanical response.

Cationic host defence peptides

Short peptides with a net positive charge with antibacterial, antifungal and/or antiviral properties. are currently being explored with several topical products in clinical development (MSB-01, DB-001), but results from proof-of-concept studies are not yet available. Skin from patients with AD presents significant differences in the microbiome compared with healthy individuals, in whom Roseomonas mucosa was found to be the most representative Gram-negative bacteria ${ }^{41}$. A product combining three strains of $R$. mucosa (FB-401) has been developed and explored, with its therapeutic activity likely consisting of activation of tissue repair and anti-inflammatory activity via Toll-like receptor 5 (TLR5) and tumour necrosis factor receptor (TNFR) ${ }^{42}$. In a phase I/IIa study in 30 patients ( 10 adults and 20 children), $60 \%$ of the adult patients showed $50 \%$ reduction in the Scoring of Atopic Dermatitis (SCORAD), while $90 \%$ of the paediatric patients achieved Eczema Area Severity Index (EASI) 50 and 30\% achieved EASI90 (see the press release from Forte Bioscience in Related links). A phase II study in children, adolescents and adults is ongoing.

Following the same strategy of bacteriotherapy, topical application of a lyophilized strain of Staphylococcus hominis A9 (ShA9) with the dual activity of killing Staphylococcus aureus and inhibiting the production of $S$. aureus-derived toxins, allowed the microbiome to recover. While well tolerated, ShA9 also induced a modest improvement of skin lesions as measured by EASI and SCORAD ${ }^{43}$

Nitric oxide is an important mediator with beneficial metabolic and potential anti-inflammatory properties.

\section{Box 1 | Controversies in the pathophysiology of AD}

There are several open questions about the mechanisms underlying atopic dermatitis (AD) (reviewed extensively elsewhere ${ }^{18}$ ). The skin microbiome is regulated on one hand by the quorum-sensing mechanisms between bacterial strains ${ }^{26}$ and on the other hand by the crosstalk between the bacteria and the skin innate immune system and epidermal Langerhans cells continuously educating the adaptive immune system. The latter mechanism is defective in $\mathrm{AD}^{250}$. A dynamic immune response is the hallmark in $A D$, but the role of potential pathogens such as Staphylococcus aureus in triggering $\mathrm{AD}$ and the stage at which this occurs are unclear $22,23,25,26,251$.

The epidermal barrier function is subjected to dual regulation ${ }^{57,252}$ : first, an intrinsic genetic mechanism whereby genes encoding structural elements such as filaggrin (FLG) are subjected to mutations or variants ${ }^{252}$ and, second, an underlying inflammation that modulates the expression of epidermal structural component ${ }^{253-256}$ and thereby further aggravates the barrier dysfunction. Whether the genetically driven epidermal barrier function or a dysregulation of the innate or adaptive immune response represent the primum movens in $A D$ remains unclear. The role of the innate immune system at later stages of the disease has to be explored. It is still not clear whether solely fighting inflammation may be necessary and sufficient for long-term control of $A D$.

Thelper $2\left(T_{H} 2\right)$ immune polarization is accompanied by $\lg$ E sensitization to environmental allergens and self proteins and has a key role in atopic disorders ${ }^{101,257}$. However, the exact role of $\mathrm{lgE}$-mediated allergy and autoimmunity in $\mathrm{AD}$ remains unclear, although it is of relevance for AD-related comorbidities.

The sequential and/or cumulative immunological events that underlie the complex clinical phenotype are key to understanding the value of targeted therapies for distinct pathways such as $\mathrm{T}_{\mathrm{H}} 2, \mathrm{~T}_{\mathrm{H}} 17$ and/or $\mathrm{T}_{\mathrm{H}} 22$ response ${ }^{124,125}$.

The generation of itch sensation and the itch-scratch cycle are increasingly considered from a neuro-immunological perspective ${ }^{29,181,182}$. The itch-scratching reflex contributes to further disruption of the epidermal barrier function, keratinocyte damage and activation of local dendritic cells, which in turn will further activate the adaptive immune response and subsequent inflammatory reaction ${ }^{29,181,182}$. However, whether itch can occur in $A D$ without inflammation is still a matter of debate.
Nitrosomonas eutropha (B244) is an ammonia-oxidizing bacterium able to produce nitric oxide, which is in clinical development for AD. In a phase IIa randomized controlled trial (RCT) in adults, B244 given as a spray induced a significant improvement of the pruritus. A similar effect on itching was reported in an open-label phase Ib paediatric trial (see the press release from AOBiome in Related links). Unfortunately, results on the clinical response of the inflammatory reaction are not available. A phase IIb dose selection trial is currently ongoing.

Decolonization of $S$. aureus can be achieved by the niclosamide ATx201, which inhibits bacterial growth. In a phase II trial, a $2 \%$ cream formulation showed significant histological and transcriptional modifications, suggesting a dual impact on the barrier function and the inflammatory reaction ${ }^{44}$.

Antimicrobial cationic host defence peptides ${ }^{45}$ are interesting candidates to control the overgrowth of $S$. aureus in $\mathrm{AD}$. Omiganan pentachloride (CLS-001) is a synthetic antimicrobial cationic peptide in clinical development as a potential topical agent for controlling dysbiosis ${ }^{46}$.

Several microbiome modulators for oral application are currently in phase I (EDP1815, STMC-103H and KBL697). Future strategies will likely be based on a better understanding of the mechanisms that underlie the modulation of the skin microbiome by bacterial quorum sensing on the one hand and host immune responses on the other ${ }^{26}$ (BOX 1).

Despite significant interest in the therapeutic potential of modulating the microbiome in general, and in strategies aiming to correct the dysbiosis assumed to be instrumental in $\mathrm{AD}$ in particular, it remains unclear whether high colonization with $S$. aureus consistently impacts the immune system and the inflammatory reaction independently of other factors such as the age of the patient, the course and duration of the disease, or epigenetic mechanisms regulating gene-gene and gene-environment interactions. There may be a window of opportunity for interventions that target the skin microbiome, potentially at an early stage of the disease in infancy. Identifying the best time point for intervention may be of crucial importance to improve disease and potentially restore an optimal adaptive immune response against $S$. aureus.

\section{Targeting the epidermal barrier function}

One of the clinical hallmarks of AD is dry, sensitive and highly permeable skin. This phenotypic characteristic is due to disturbance of epidermal barrier function (BOX 1) owing to a dual mechanism ${ }^{1,2,18}$ : first, a genetic origin with mutations in genes encoding functionally important structures such as filaggrin (FLG); and second, an inflammatory origin with key mediators such as IL-13 negatively impacting epidermal barrier function.

There are two approaches to restore the epidermal barrier function in AD: first, the development of products specifically addressing the biochemical alterations, although the lack of understanding of the functional genetics of the multiple structures involved in these defects represents a major hurdle; and second, effective control of the underlying inflammatory reaction 
Microbiome
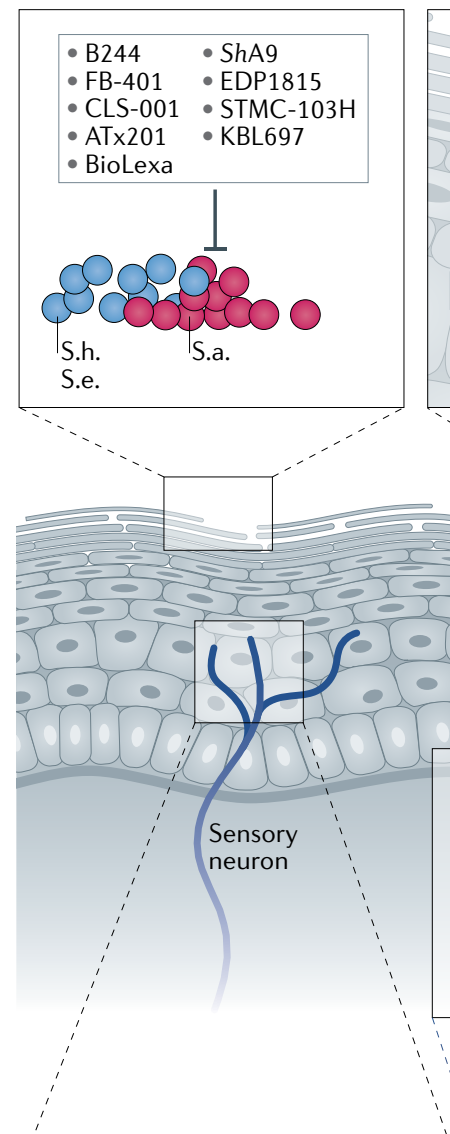

Pruritus

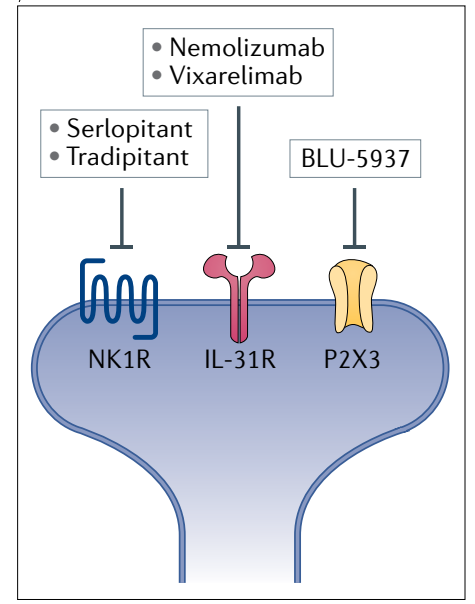

,

T cell migration

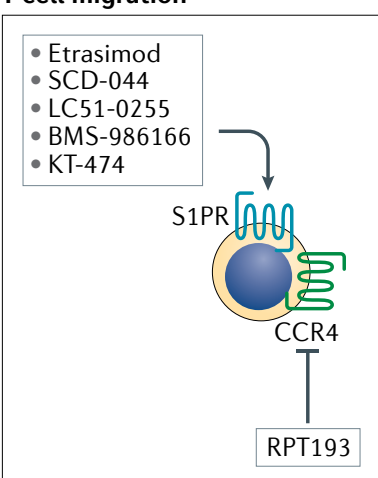

Innate immune response

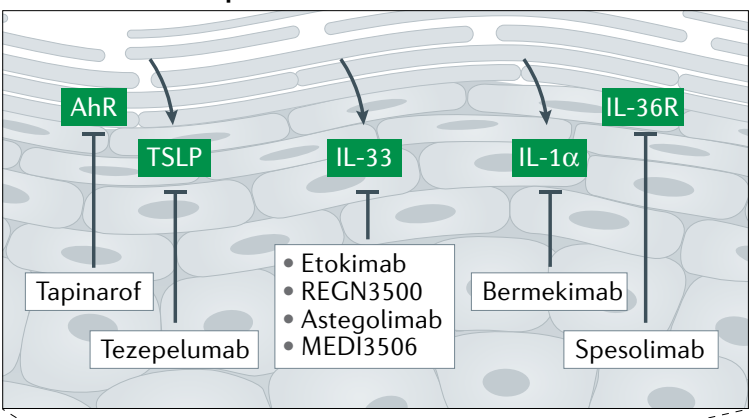

Epidermis

Janus kinase inhibitors

\begin{tabular}{|c|c|c|c|}
\hline (JAK1) (JAK3 & (JAK1) & (JAK2 JAK2 & (AK1) \\
\hline $\begin{array}{l}\text { Pan-JAKi } \\
\text { - Delgocitinib } \\
\text { - CEE312 } \\
\text { - Jaktinib } \\
\text { - Cerdulatinib }\end{array}$ & $\begin{array}{l}\text { JAK1/JAK2 } \\
\text { - Baricitinib } \\
\text { - Ruxolitinib }\end{array}$ & $\begin{array}{l}\text { JAK1 } \\
\text { - Upadacitinib } \\
\text { - Abrocitinib } \\
\text { - SHR0302 }\end{array}$ & $\begin{array}{l}\text { JAK1/TYK2 } \\
\text { Brepocitinib } \\
\text { JAK1/JAK3 } \\
\text { ATI-1777 }\end{array}$ \\
\hline
\end{tabular}

Dermis

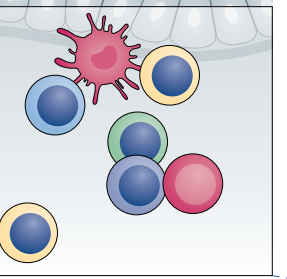

Adaptive immune response

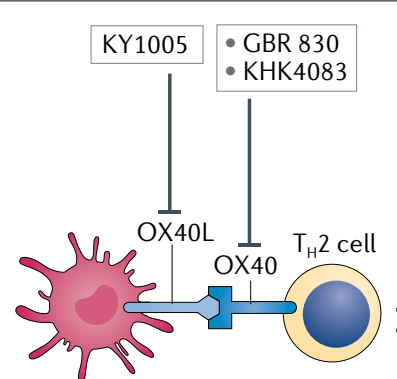

Dendritic cell

$\because$

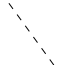


$\varangle$ Fig. 2 | Therapeutic strategies for atopic dermatitis. Multiple strategies aimed at correcting the skin dysbiosis by microbiome manipulation are currently in development either by topical application or by oral administration. The aim is to reduce the overgrowth of Staphylococcus aureus (S.a.) and/or to favour the recovery of the commensals Staphylococcus hominis (S.h.) and Staphylococcus epidermidis (S.e.). The innate immune response is assumed to be instrumental at the very early stage of $A D$, and targeting the aryl-hydrocarbon receptor (AhR) and alarmins represents an appealing strategy of intervention. The complexity of the adaptive immune response offers multiple opportunities for targeted therapies using biologics against cytokines and their respective receptors. As T cells are the effectors in the inflammatory reaction, impacting on their migratory activity from the lymph nodes via modulation of the sphingosine 1-phosphate receptor (S1PR) or into the skin via the $\mathrm{C}-\mathrm{C}$ chemokine receptor 4 (CCR4) is an emerging approach. Besides biologics, another strategy to affect the pathways involved in the generation of inflammation is the use of kinase inhibitors that are differentially selective for Janus kinases (JAKs) (JAKi) involved in the signal transduction of cytokine receptors. Other inhibitors address kinases involved in pathways related to the nerve growth factor, such as the tropomyosin receptor kinase (TRK) or Bruton tyrosine kinase (BTK) involved in the signal transduction of the $\mathrm{B}$ cell receptor or the high-affinity receptor for $\lg \mathrm{E}$ expressed in mast cells and dendritic cells. Histamine receptor $4(\mathrm{H} 4 \mathrm{R})$ is widely expressed and is an interesting target as it is involved in immunomodulatory mechanisms. Another popular approach to reduce inflammation in AD is to use inhibitors of phosphodiesterase 4 (PDE4) as they increase the cellular levels of cAMP and thereby contribute to the generation of anti-inflammatory cytokines. As sensing neurons in the skin can be activated by multiple mediators generated during the inflammatory reaction, several strategies targeting the generation of itching have been developed, including blockade of IL-31 receptor (IL-31R), neurokinin 1 receptor (NK1R) and purinoreceptor 3 (P2X3). LXR, liver X receptor; mlgE, membrane form of IgE; OX40L, OX40 ligand; $T_{H}$ cell, T helper cell; TSLP, thymic stromal lymphopoietin.

\footnotetext{
Alarmins

Proinflammatory cytokines and danger signals produced in the context of the innate immune response.
}

Hidradenitis suppurativa Chronic inflammatory skin disorder typically affecting the groin, armpits and buttocks leading to painful nodules and abscesses that heal with scarring of the skin. (see below), although this may not lead to full correction of barrier function.

Therefore, individually and empirically adapted skin care using emollients or moisturizers to complement the control of inflammation still remains the only approach to improve barrier function, dryness and water loss and is qualified as basis therapy ${ }^{35}$. In line with this concept, even a simple product such as petrolatum has been shown to modulate the antimicrobial and epidermal barrier function ${ }^{47}$. After initial promising results using such emollients and moisturizers in the prevention of $\mathrm{AD}$ in newborns at high risk $^{48,49}$, a more recent report has questioned this strategy $y^{50,51}$.

\section{Targeting the innate immune response}

The role of the innate immune system in the early phase of $\mathrm{AD}$ was demonstrated using animal models $\mathrm{s}^{52-54}$ and is likely of clinical relevance in infancy ${ }^{55}$. The aryl-hydrocarbon receptor (AhR) is a ligand-activated transcriptional factor with a Janus-faced role in physiology and the pathophysiology of several skin disorders including $\mathrm{AD}^{56,57}$. It exerts pro- and anti-inflammatory activities, depending on the cell type, the micromilieu and the ligand, that is, exogenous and endogenous metabolites and agents ${ }^{58}$. As it is expressed in keratinocytes and resident epidermal dendritic cells (DCs), AhR represents an ideal target for a topical pharmacological approach. Interestingly, coal tar has been shown to bind to AhR and to restore the expression of filaggrin, as shown by immunohistochemistry and transcriptomic analysis ${ }^{59}$. Tapinarof (also known as benvitimod) is a natural AhR agonist ${ }^{60}$ that significantly reduces inflammatory responses both in animal models and in human skin when used topically. In a phase IIb trial, the best results were obtained with a $1 \% \mathrm{cream}^{61,62}$, with
$53 \%$ of the patients reaching the primary end point of Investigator Global Assessment (IGA) 0/1 versus 28\% in the placebo group. These data suggest that this compound represents a promising new option for topical therapy of both $\mathrm{AD}$ and psoriasis ${ }^{63}$, another chronic inflammatory skin disorder.

Mutations or variants of genes such as SPINK5 favour the generation of allergen-independent, nonspecific inflammation, providing a pro-T helper $2\left(\mathrm{~T}_{\mathrm{H}} 2\right)$ micromilieu by virtue of keratinocyte-derived alarmins such as thymic stromal lymphopoietin (TSLP), IL-33 and IL-25 (REFS ${ }^{52,64}$ ). Given their key role in initiation of the skin-derived immune response, alarmins are interesting therapeutic targets. The anti-TSLP antibody tezepelumab (AMG 157) has shown convincing results in patients with severe and uncontrolled allergic asthma ${ }^{65,66}$. By contrast, a phase IIa study in patients with $\mathrm{AD}$ showed $64.7 \%$ of patients reaching the EASI50 end point versus $48.2 \%$ in the placebo group ${ }^{67}$. However, the interpretation of these data is difficult as all patients were allowed to use TCSs.

Because of its pleiotropic biological activities, targeting IL-33 represents another interesting strategy to affect early mechanisms within the innate immune response. Five different biologics are currently in clinical development. In a proof-of-concept study with a single application of the anti-IL-33 antibody etokimab (ANB020) in 12 patients with moderate or severe $\mathrm{AD}, 33 \%$ of patients reached the primary end point EASI75 and $83 \%$ reached EASI50 $\left(\right.$ REF $\left.^{68}\right)$. Interestingly, this improvement lasted for up to 140 days after the single dose. Etokimab inhibited direct, as well as CXCR1-dependent, neutrophil migration in vitro. Whether this observation is relevant for later phases of $\mathrm{AD}$ in which neutrophils are only rarely seen in the inflammatory infiltrate remains to be explored. However, in a larger phase IIa study (ATLAS study) with 300 adult patients, the primary end point was not reached (see the press release from AnaptysBio in Related links). Astegolimab (MSTT1041A/AMG282), MEDI3506 and REGN3500 are additional anti-IL-33 antibodies in proof-of-concept studies for which the results are not yet available.

IL- $1 \alpha$ is a proinflammatory cytokine released by keratinocytes after injury and by skin dysbiosis ${ }^{69}$. As one of the first and most important mediators in antigen presentation and induction of the inflammatory cascade, IL-1 $\alpha$ has been considered as a therapeutic target in $\mathrm{AD}^{69}$. The anti-IL-1 $\alpha$ antibody bermekimab (MABp1) was initially developed for oncological indications $s^{70,71}$ and recently for hidradenitis suppurativa ${ }^{72}$. In an openlabel phase IIa study in eight patients, the safety profile of bermekimab was acceptable, and results for the highest dose indicated promising efficacy, with $39 \%$ of patients reaching the status of clear or almost clear (IGA 0/1) as well as a strong reduction in itching, with $68 \%$ improvement in the pruritus numerical rating scale (NRS) (see results under NCT03496974).

IL-36 is another player in the innate immune system that is upregulated in the skin of psoriasis as well as $\mathrm{AD}$. Interestingly, in a mouse model, colonization with $S$. aureus induces IL-36R- and IL-1R-dependent inflammation ${ }^{73}$. Therefore, the anti-IL-36R antibody 


\section{Box 2 | Disease dimensions, established instruments and end points to assess AD}

\section{Disease dimensions}

Schematically, atopic dermatitis (AD) recognizes several dimensions: the clinical signs (erythema, oedema/induration/papulation, excoriation, lichenification, oozing and dryness); the symptoms (pruritus/itching and related sleeplessness) and the patient-reported outcomes (PROs) of quality of life and disease control.

These dimensions serve as the basis for objective and subjective assessment instruments from which the end points used in clinical trials are derived. The Harmonising Outcome Measures for Eczema (HOME) initiative has established a core outcome set of tools and end points to be used in clinical trials ${ }^{258-261}$ and are discussed in detail elsewhere ${ }^{37}$. For regulatory purposes, the end points based on clinical signs are typically considered as primary efficacy end points while PROs are secondary end points.

\section{Established instruments for assessment and derived end points} Clinical signs

- The validated Investigator Global Assessment (vIGA) is a simple objective measure providing an overall evaluation. It uses a 5 -point scale (clear $=0$; almost clear $=1$; mild = 2; moderate $=3$; severe $=4$ ). The efficacy end point based on vIGA, IGA 0/1 gives the percentage of patients reaching the status of clear (rated as 0 ) or almost clear (rated as 1 ) and a minimum 2-grade improvement. IGA $0 / 1$ is mandatory for the FDA as primary end point for phase III trials. It is currently not accepted by the EMA as a primary end point.

- The Eczema Area Severity Index (EASI) considers the average severity of individual clinical signs (see above) ( $0-3$ scale) and surface involved in four body regions (head and neck, trunk, upper and lower extremities), the maximum being 72 points. Clinical end points based on EASI: the percentage change in EASI from baseline and the percentage of patients reaching 75 percentage (EASI75) improvement from baseline are the most currently used end points. The more stringent EASI90 is almost equivalent to the above-mentioned IGA 0/1

- The Scoring of Atopic Dermatitis (SCORAD) is based on the intensity of clinical signs ( $0-3$ scale) and the disease extent (involved surface according to the rule of 9 ). The maximum points are 103. It also considers itch and sleeplessness as subjective symptoms and is evaluated by visual analogue scales. The latter two items are excluded in the so-called objective SCORAD (oSCORAD), the maximum points being 83 . Clinical end points based on SCORAD: the percentage change in SCORAD from baseline is frequently used in clinical trials. SCORAD75 is defined as the percentage of patients experiencing an improvement of at least $75 \%$ from the baseline value.

There is good correlation between the various scoring tools that are used to stratify patients according to severity. Mild forms are defined as vIGA $=2$; EASI $<7$ or SCORAD $<25$; moderate forms are defined as vIGA $=3 ; 7<\mathrm{EASI}<21$ or $25<\mathrm{SCORAD}<50$; severe forms are defined as vIGA $=4$; EASI $>21$ or $S C O R A D>50$. The cut-off points to define moderate to severe forms are defined as $\mid G A \geq 3 ; E A S I \geq 16$ or $S C O R A D \geq 50$.

Of note, using these instruments is felt to be complex and time consuming by most practitioners outside of the trial setting. A simple tool for daily record keeping is still lacking.

\section{Symptoms}

In the Peak Pruritus Numerical Rating Scale (PP-NRS-11), the patient rates their peak itch sensation during the previous $24 \mathrm{~h}$ on a $0-10$ scale. A decrease of at least 4 points is considered a clinically relevant end point. This tool correlates weakly with objective tools such as EASI and vIGA.

\section{Quality of life}

- The Dermatology Life Quality Index (DLQI) is a validated and widely used 10-item questionnaire with paediatric versions (0-3 and 4-16 years). A variation of 4 points is considered a clinically meaningful end point.

- The Patient-Oriented Eczema Measure (POEM) ${ }^{262}$ is a validated tool in which the patient self-assesses how many days they experienced seven distinct items (itch, sleep disturbance, bleeding, weeping/oozing, cracking, flaking, dryness of the skin) during a period of 1 week. The maximum score is 28 points. There is good correlation with other PROs.

\section{Disease control}

Long-term control is a key aspect in the management of AD. Only recently, two similar instruments have been developed.

- The 7-item Recap of Atopic Eczema (RECAP) validated in adults and children. There is good correlation with POEM and other PROs.

- The 6-item Atopic Dermatitis Control Tool (ADCT) validated for adults. spesolimab, which has been successfully tested in a rare form of pustular psoriasis ${ }^{74}$, has been explored for $\mathrm{AD}$ in a phase IIa study with 51 patients, the results of which are expected by the end of 2021 .

It remains to be clarified which pathways within the innate immune response are relevant in the initial phase of AD in infancy and later in the course of the disorder, which is crucial to understand for the design of successful targeted therapies. As, for regulatory reasons, proof-of-concept studies are primarily performed in adults, the limited efficacy observed in some studies such as those targeting TSLP or IL-33 may not predict their efficacy in an early phase of the disease, that is, in the paediatric population.

\section{Targeting the adaptive immune response}

The heterogeneity of the clinical phenotype of AD most probably reflects the highly complex pathophysiology. The underlying 'march of the adaptive immune system' starts from antigen presentation and affects varrious pathways, ultimately offering distinct therapeutic options ${ }^{18,19,75-77}$. Besides $\mathrm{T}_{\mathrm{H}} 2$ immune polarization, whereby IgE, IL-4, IL-5 and IL-13 and/or their receptors are potential targets, multiple other mediators - some of them more related to psoriasis such as IL-17, IL-23, IL-36 or IL-22 - are the subjects of clinical development strategies.

Antigen presentation. Antigen presentation has a crucial role in the generation and maintenance of the various pathways of the adaptive immune response, ultimately leading to inflammation. Strategies that aim to modulate the responding $\mathrm{T}$ cells are an attractive option, provided that they avoid harmful immunosuppression. OX40 is a costimulatory molecule and member of the TNF receptor family (TNFRS4). It is transiently expressed on T cells upon activation and contributes to clonal expansion, survival and memory formation. Initial studies with antibodies directed against OX40 (GBR 830 and KHK4083) or its ligand OX40L (KY1005) expressed on DCs have shown promising results. In a phase IIa trial, intravenous GBR 830 was well tolerated and significantly improved the lesions with an EASI50 in 78\% of patients who received the antibody, compared with $38 \%$ in the placebo group. The antibody also improved the gene signatures in the skin ${ }^{78}$. Similarly, in a phase Ib trial, KHK4083 resulted in a $74 \%$ reduction in the EASI score, and the IGA $0 / 1$ was reached in $35 \%$ of the patient $\mathrm{s}^{79}$. Results from the phase IIb trial from both agents are pending.

Interesting results were also seen in a phase IIa study using the non-depleting anti-OX40L biologic KY1005. This antibody inhibits the effector $\mathrm{T}$ cell ( $\mathrm{T}_{\text {eff }}$ cell) response and maintains regulatory $\mathrm{T}$ cell $\left(\mathrm{T}_{\mathrm{reg}}\right.$ cell) activity. A low-dose regimen resulted in a mean percentage change of EASI from baseline of $80.1 \%$ versus $49.4 \%$ in the placebo group. IGA $0 / 1$ was reached in $44 \%$ of those who received KY 1005 versus $8 \%$ in the placebo group (see the Kymab press bulletin in Related links).

As it is assumed that affecting the OX40-OX40L interaction affects not only the core $\mathrm{T}_{\mathrm{H}} 2$ response but also other $\mathrm{T}$ cell subsets, this strategy has interesting 
therapeutic potential along the dynamics of the immune response. It may potentially be highly relevant for mechanisms involved in the putative immunological march underlying the individual course of the disease. However, since antigen presentation is also an important step in antitumoural defence, the long-term safety profile of drugs that affect the OX40-OX40L interaction will be key, particularly in older patients in whom the incidence of unrecognized and diagnosed tumours is significantly higher. On the other hand, the long-term data should also demonstrate whether this strategy has the potential for disease modification, at least in a yet-to-be-defined subgroup of patients.

$T_{H} 2$ cytokines and their receptors. $\mathrm{A}_{\mathrm{H}} 2$ immune response is considered the core pathway leading to cutaneous inflammation in AD. IL-4, IL-13 and IL-5 or their respective receptors are the focus of drug development strategies that aim to modulate the $\mathrm{T}_{\mathrm{H}} 2$ response $\mathrm{r}^{80,81}$.

Dupilumab binds to IL-4Ra, the chain common to the type I (IL-4R $\alpha / \mathrm{IL}-2 \mathrm{R} \gamma$ ) and type II (IL-4R $\alpha$ / IL-13Ra1) receptors for IL-4 and IL-13 (REFS ${ }^{81,82}$ ). It is approved for AD in many countries and real-world data support the efficacy reported in the phase III programme in adults ${ }^{83-86}$. As AD is a typical disease of childhood, a focus is now placed on the ongoing staggered paediatric investigational programmes, the most advanced being in the USA and the EU where dupilumab is now approved for children aged 6 years and older. Studies exploring the pharmacokinetics, safety and efficacy in children aged 6 months to 6 years are ongoing to provide for the first time an option for systemic therapy in this important population.

CBP-201 is another IL-4R $\alpha$ antagonist with interesting results in a phase Ib study in 31 patients. Although the mode of action is theoretically similar to that of dupilumab, it seems to have a faster onset of action. After only 4 weeks of therapy, IGA $0 / 1$ was seen in up to $50 \%$ of patients receiving CBP-201 versus $13 \%$ in the placebo group. The mean reduction in EASI from baseline was $74 \%$ versus $33 \%$ in the placebo group. There were no safety signals reported and a dose-finding phase IIb study is ongoing. AK120 is another antibody directed against IL-4Ra currently in phase Ib studies in healthy subjects and patients with moderate-to-severe $\mathrm{AD}$.

ASLAN004 is a fully humanized antibody directed against IL-13Ral, thereby blocking the binding of IL-4 and IL-13 on the type II receptor (IL-4R $\alpha /$ IL-13R $\alpha 1$ ). Owing to the more selective binding compared with dupilumab, ASLAN004 may provide the option of a low-dose regimen and a better safety profile. An interim data analysis from a phase Ib study showed that the compound is well tolerated and provided promising efficacy data, with $67 \%$ of the patients achieving EASI75 versus $0 \%$ in the placebo group (see the ASLAN press release in Related links).

Whereas IL-4 seems to be more relevant for the central part of the $\mathrm{T}_{\mathrm{H}} 2$ pathway ${ }^{87}$, IL-13 has been identified as the key $\mathrm{T}_{\mathrm{H}} 2$ cytokine mediating the skin inflammation in $\mathrm{AD}^{88,89}$. Two antibodies that specifically target IL-13 are in late-stage clinical development. Tralokinumab, which was recently backed by a positive opinion from the EMA (EMA/CHMP/202204/2021), is a fully humanized antibody targeting IL-13 that blocks its binding to both IL-13Ra1 and IL-13a2 receptor chains $^{90,91}$. In the phase III pivotal monotherapy studies, at week 16, tralokinumab showed superiority to placebo, with IGA 0/1 being reached in 16\% (ECZTRA1) and $22 \%$ (ECZTRA2) of the patients receiving the antibody versus $7 \%$ and $11 \%$ in the respective placebo groups. Similarly, EASI75 was reached in $25 \%$ and $33 \%$ of patients receiving treatment in the two trials versus $13 \%$ and $11 \%$ receiving placebo, respectively. Interestingly after re-randomization at week 16 followed by maintenance treatment, the clinical response further improved, with IGA $0 / 1$ being reached in $51 \%$ (ECZTRA1) and 59\% (ECZTRA2) of the patients ${ }^{92}$. This suggests that tralokinumab develops its full potential at a later time point. In the pivotal studies with dupilumab, $11 \%$ of the patients developed eye disorders (for example, conjunctivitis, keratoconjunctivitis and keratitis); this adverse event of special interest (AESI) has been attributed to its IL-13 blocking activity ${ }^{93}$. Higher rates were described in long-term studies and in realworld reports ${ }^{83-86}$ but interestingly not in asthma ${ }^{94}$. The mean rate of eye disorders for both ECZTRA1 and ECZTRA2 studies with tralokinumab at week 16 was $7.6 \%$ versus $3 \%$ in the placebo group. Data from longterm drug exposure will provide more information in this regard.

Lebrikizumab is another fully humanized anti-IL-13 antibody that does not block the binding of the cytokine to the receptor but instead impairs the heterodimerization of IL-4R $\alpha$ and IL-13Ra1, thereby inhibiting signal transduction ${ }^{91,95}$. Lebrikizumab does not affect the binding of IL-13 to the IL-13Ra2 receptor chain, the biological role of which remains unclear ${ }^{81}$. In a phase IIb dose-finding study, the best clinical response for the primary end point (percentage change in EASI) was obtained with $250 \mathrm{mg}$. In this group, $72 \%$ improvement was shown versus $41 \%$ in the placebo group ${ }^{96}$. The efficacy was mirrored by a rapid improvement in the pruritus NRS. The rate of conjunctivitis was low and the drug was otherwise well tolerated.

The importance and efficacy of targeting the $\mathrm{T}_{\mathrm{H}} 2$ cytokines IL-4 and IL-13 and their receptors is now well recognized. Among the drugs considered above, dupilumab recently received an approval extension for the paediatric population in AD. Dupilumab is also approved for atopic comorbidities such as allergic asthma and nasal polyposis, clearly conferring a broad therapeutic profile to this compound. It is still unclear which role the anti-IL-13 strategy plays in allergic asthma and other atopic comorbidities and whether tralokinumab, lebrikizumab and ASLAN004 will be able to efficiently treat dupilumab partial responders and non-responders. The distinct modes of action of dupilumab (blocks IL-4 and IL-13 binding to the type I and type II receptors with no interaction with IL-13Ra2 chain), tralokinumab (blocks binding of IL-13 to IL-13Ra1 and IL-13a 2 chains), lebrikizumab (blocks the association of type II receptor subunits after binding of IL-13, no interaction with IL-13Ra2 chain) and ASLAN004 (blocks the binding of IL-4 and IL-13 on the type II receptor, no interaction 
with IL-13Ra2 chain) are well established. From their clinical development programmes, it is expected that important new insights into the respective roles of IL-4 and IL-13 in the central and peripheral $\mathrm{T}_{\mathrm{H}} 2$ immune responses, and into the respective roles of type $\mathrm{I}$ and type II receptors as well as IL-13Ra2 in the regulation of skin inflammation in humans, will be obtained.

Eosinophils and their degradation products eosinophil-derived neurotoxin and eosinophil cationic protein are detectable in the inflammatory infiltrate of $\mathrm{AD}$ and correlate with disease severity ${ }^{97,98}$. Therefore, eosinophils are considered as potential effector cells, and therapeutic approaches targeting IL-5, the most important cytokine involved in eosinophil biology, were designed accordingly. However, in a first proof-ofconcept study of the anti-IL-5 antibody mepolizumab, although eosinophilia was significantly reduced ${ }^{99}$, the drug failed to demonstrate a significant decrease in the SCORAD, the pruritus scoring or the severity biomarker TARC when compared with baseline.

In contrast to mepolizumab, benralizumab binds to the IL-5R $\alpha$ chain expressed on eosinophils and basophils and initiates antibody-dependent cell-mediated cytotoxicity, ultimately leading to their depletion. The drug is already approved for severe forms of eosinophilic asthma and a phase IIa study in AD exploring its efficacy in a maintenance regimen (HILLIER study) is ongoing.

Immunoglobulin E. A significant part of the sensitization process leading to the generation of IgE responses against environmental allergens (including food allergens) $)^{100}$ as well as against self proteins ${ }^{101}$ correlates with cutaneous inflammation and overall severity ${ }^{102,103}$. Moreover, provocation tests with food allergens as well as with aeroallergens induce exacerbation in a subgroup of $\mathrm{AD}$ patients ${ }^{104,105}$. These observations imply a role for IgE-bearing antigen-presenting epidermal DCs such as Langerhans cells in the capture and presentation of allergens to $\mathrm{T}$ cells ${ }^{106}$. Hence, it is intriguing that strategies aimed at depleting IgE with the anti-IgE biologic omalizumab failed to show convincing results in proofof-concept studies and single cases ${ }^{107,108}$. However, clinical improvement was shown in a small series of patients using omalizumab and/or immunoadsorption ${ }^{109-112}$. The Atopic Dermatitis Anti-IgE (ADAPT) study was designed to verify the hypothesis that IgE may instead have a role in the paediatric population ${ }^{113}$. Indeed, using weight-adapted doses of omalizumab in children with high total serum IgE, there was a significant difference in the change from baseline for the objective SCORAD as primary end point compared with the placebo group ${ }^{114}$. Similar results were obtained for the EASI score. These encouraging efficacy data were confirmed by reduced use of TCSs as well as improved quality of life in the omalizumab-treated group.

Another approach is to inhibit IgE synthesis by targeting IgE-committed B cells expressing a membrane form of $\operatorname{IgE}$ (mIgE). Anti-CemX (FB825) is directed against $\mathrm{mIgE}$ and has been reported to deplete IgE-committed $B$ cells and lymphoblasts by apoptosis. This approach would lead to long-term reduction in IgE-mediated reactions in allergic individuals, including patients with $\mathrm{AD}^{115}$. The phase IIa study is ongoing.
Although increased IgE serum level is a hallmark of a $\mathrm{T}_{\mathrm{H}} 2$ immune response and specific IgE to at least one allergen can be found in the vast majority of $\mathrm{AD}$ patients, its role in this disorder and the strategies aimed to target IgE are still a matter of debate. The lack of efficacy may be due to a limited ability of the approved doses of biologics such as omalizumab to neutralize the high levels of total IgE typically seen in polysensitized patients with $\mathrm{AD}$. In this case, the use of anti-IgE strategies would be more meaningful in those patients with oligosensitization and specific IgE directed against a few but clinically relevant allergens for a given individual patient. Another explanation could be that IgE-mediated allergic reactions to environmental allergens become irrelevant after a long disease duration, particularly in adults.

IL-22 and its receptor IL-22R. Besides $\mathrm{T}_{\mathrm{H}} 2$ cytokines, IL-22 is an important part of the transcriptomic signature in $\mathrm{AD}^{116,117}$. This cytokine is induced by staphylococcal exotoxins ${ }^{118}$ in numerous inflammatory cells, including $\mathrm{T}_{\mathrm{H}} 1$ and $\mathrm{T}_{\mathrm{H}} 17$ cells. Circulating IL- 22 correlates with the severity of $\mathrm{AD}$ and appears as a key driver in the inflammatory reaction ${ }^{116,119}$. In keratinocytes, IL-22 exerts multiple biological activities, including their proliferation and downregulation of filaggrin expression $^{120,121}$. Thus, targeting IL-22 or its receptor seems an attractive therapeutic approach in $\mathrm{AD}$. In a first proof-of-concept study, the anti-IL-22 antibody fezakinumab (for which clinical development programmes have been discontinued in rheumatoid arthritis and psoriasis) was investigated in moderate to severe AD. When considering the entire study population, there was no significant difference in the change of SCORAD compared with baseline as the primary end point. However, encouraging results were seen in patients with severe forms (SCORAD >50) where the mean decline in SCORAD was significantly better than in the placebo group $^{122}$. The limitations of this study were small sample size $(n=60)$ and a time point likely too early to capture the clinical effects.

IL-22 binds to IL-22R1, which subsequently heterodimerizes with IL-10R2. IL-22R1 also associates with IL-20R2 to bind to IL-20 and IL-24, which can also bind to IL-20R1-IL-20R2 receptor complexes. Thus, targeting IL-22R1 is an appealing strategy to block the biological activity of IL-22 in AD with less impact on the biological activity of IL-20 and IL-24. This is the strategy followed by the antibody LEO 138559 directed against IL-22R1, which is currently in phase I studies.

The 'psoriasis pathway': IL-23 and IL-17. Besides being the core pathway in psoriasis, there is increasing evidence that the IL-23-IL-17 axis as well as IL-36 (see above) may have a role, at least in some AD subtypes such as the so-called intrinsic form and in Asian patients ${ }^{73,103,117,123-125}$. Two studies have been initiated using the anti-IL-17A antibody secukinumab in patients with moderate to severe AD. In a placebo-controlled randomized phase II investigator-initiated study in patients, this compound did not show clinical efficacy or induce any significant changes in several mechanistic investigations such as epidermal thickness, changes 
in the composition of the cellular infiltrate or analysis of the transcriptomic signatures ${ }^{126}$. Another phase IIa study with 22 patients was completed but the results are not available. As part of the same pathway, IL-23 is another candidate for intervention in $\mathrm{AD}$. A proofof-concept study exploring the putative efficacy of the anti-IL-23 antibody risankizumab has been initiated.

Restoring $T_{\text {reg }}$ cell function. Similar to autoimmune disorders, it is assumed that in allergic diseases such as $\mathrm{AD}, \mathrm{T}_{\text {reg }}$ cells do not properly exert their dampening activity, allowing immune polarization. A strategy aimed at enforcing the $\mathrm{T}_{\text {reg }}$ cell limb of the immune system would restore tolerance and repress chronic inflammation. The pegylated recombinant human IL-2 (rhIL-2; LY3471851) has been designed to target the IL-2 receptor complex on T cells leading to activation and proliferation of $\mathrm{T}_{\text {reg }}$ cells. Besides systemic lupus erythematosus, ulcerative colitis and psoriasis, LY3471851 is currently in a phase Ib trial to test its safety and tolerability as well as the hypothesis that this compound could restore tolerance and improve AD.

Phosphodiesterase 4. In the early 1980s, increased PDE4 activity was described as one of the first candidate targets for the therapy of allergic disorders including $\mathrm{AD}^{126,127}$. Meanwhile, PDE4 inhibitors are known to have a wide spectrum of interesting therapeutic effects related to downregulation of inflammatory cytokines involved in pulmonary, neurological, rheumatoid, gastrointestinal and dermatological disorders ${ }^{128}$. Paradoxically, the oral PDE4 inhibitor apremilast is already approved to treat moderate to severe forms of psoriasis while its development in AD fails to progress. Pilot open-label studies of this PDE4 inhibitor provided promising results ${ }^{129,130}$. However, a phase II RCT in AD showed a significant improvement only for the high dose compared with placebo (32\% reduction in EASI score versus $11 \%$ in the placebo group), but the study was discontinued owing to adverse events ${ }^{131}$.

An alternative approach is the topical administration of PDE4 inhibitors, thereby avoiding the typical gastrointestinal adverse events observed with systemic application. These compounds are typically developed for mild to moderate forms of $\mathrm{AD}$. Besides the approved drug crisaborole, several other compounds are currently in development. Promising results have been obtained initially with lotamilast (RVT-501/E6005) in a cream in Japanese adults and children ${ }^{132,133}$. The results of a recent phase II study exploring an ointment formulation in adolescents and adults with mild to moderate $\mathrm{AD}$ are not yet available.

Difamilast (OPA-15406/MM36) administered as a cream has been shown to be effective in adolescents and adults in a phase IIa study ${ }^{134}$. A maximal-use phase II study in Japanese children and adolescents confirmed the good safety and tolerance profile of this compound ${ }^{135}$. Interestingly, up to $40 \%$ of patients reached the stringent clinical efficacy end point IGA $0 / 1$, in contrast to only $8 \%$ in the placebo group, along with a greater decrease in the other secondary end points (EASI, visual analogue scale pruritus and Patient-Oriented Eczema Measure
(POEM)) compared with placebo. These promising results were confirmed in two phase III pivotal trials completed in Japan (see the press release in Related links).

In a proof-of-concept study with a limited number of patients, administration of the PDE4 inhibitor roflumilast (AQR-151) as a cream failed to reach the primary end point (change in EASI from baseline) and there were no safety signals.

LEO 29102 is a PDE inhibitor with selectivity for the PDE4D isoform ${ }^{136}$. In a phase II study, different doses of the drug were applied and compared with application of the topical calcineurin inhibitor pimecrolimus. Although the highest dose showed an interesting effect on the pruritus score, the absolute change in EASI from baseline was not significant when compared with placebo and thereby not superior to pimecrolimus (NCT01037881). Further ongoing phase II studies include the new PDE4 inhibitors Hemay-808 and PF-07038124, for which results are not yet available.

Despite the hopes invested in the development of several PDE4 inhibitors, while the safety profile seems acceptable for the topical formulation, their overall efficacy seems rather limited. It therefore seems that these compounds will hardly be competitive for topical steroids and even possibly for topical calcineurin inhibitors.

Histamine H4 receptor. Four types of histamine receptor (H1R-H4R) have been described, all of which are G protein-coupled receptors ${ }^{137}$. H1R in the brain is involved in internal clock modulation, while in the skin, it induces pruritus but also has immunomodulatory activities. H2R is mainly localized in the gastrointestinal tract and other organs, where it regulates smooth muscle relaxation. H3R is localized in the central nervous system, where it regulates the synthesis of histamine. H4R exerts immunoregulatory activities on leukocytes and represents an interesting target for immunomodulation. After the reference compound JNJ-7777120, further selective H4R antagonists ${ }^{138}$ have been introduced into clinical development for distinct indications such as neurological disorders ${ }^{139,140}$, asthma ${ }^{141,142}$ and for inflammatory skin disorders, including $\mathrm{AD}^{143-146}$. While $\mathrm{H} 4 \mathrm{R}$ antagonism alone seems promising in reducing the scratching reaction in animal models of skin inflammation, it only improves inflammation in combination with $\mathrm{H} 1 \mathrm{R}$ antagonism ${ }^{147}$. Conversely, conflicting data were reported from a phase IIa study of the H4R antagonist adriforant (formerly ZPL-389); a modest but significant improvement in the SCORAD was shown, but the reduction in pruritus was not significant ${ }^{148}$. A phase IIb dose-ranging study with adriforant was terminated and the programme was suspended. LEO 152020 is another oral H4R antagonist currently in phase I.

$T$ cell migration. Antigen-specific $\mathrm{T}_{\mathrm{H}} 2$ cells represent a numerically important component of the dermal and epidermal infiltrates in $\mathrm{AD}^{18}$. By the production of a large variety of mediators, $\mathrm{T}$ cells contribute to the generation of a dynamic and disease-specific inflammatory micromilieu with a strong impact on epidermal barrier function. $T$ cells are recruited by locally 
Chemotactic factors

Mediators leading to chemotaxis, that is, the migration and attraction of cells, typically along a concentration gradient. produced chemotactic mediators, and inhibition of their migration represents an appealing strategy $\mathrm{y}^{18,54,149,150}$. Prostaglandin D2 and its receptor (PGDR2/CRTH2) play an important role in the generation of inflammation ${ }^{151}$. CRTH2 is preferentially expressed on $\mathrm{T}_{\mathrm{H}} 2$ cells $^{152,153}$ and, as shown in vitro and in animal models ${ }^{154,155}$, has an important role in $\mathrm{T}_{\mathrm{H}} 2$-mediated inflammation of $\mathrm{AD}$ by directing their migration into the skin. However, both CRTH2 antagonists fevipiprant (QAW039) and temapiprant (OC000459) failed to significantly improve $\mathrm{AD}$ in phase II studies.

Like CRTH2, the C-C chemokine receptor 4 (CCR4/ CD194) is a hallmark of memory $\mathrm{T}_{\mathrm{H}} 2$ cells and binds to the chemokines RANTES, MCP1, CCL22/MDC and CCL17/TARC. These mediators are produced in high amounts in $\mathrm{AD}$ and correlate with the severity of $\mathrm{AD}^{156,157}$. Hence, blocking CCR4 is an interesting option for reducing inflammation in $\mathrm{AD}^{150}$. In preclinical experiments, RPT193, a small-molecule CCR4 antagonist, selectively blocks the recruitment of $\mathrm{T}_{\mathrm{H}} 2$ cells in allergic diseases. In these animal models, the activity was similar to that of an anti-IL-13 antibody (see information in Form 8-K from Rapt Therapeutics in Related links). First reports from a phase I study showed no serious adverse events in 64 healthy subjects after single and multiple dosing (see the press release from RAPT Therapeutics in Related links). Phase II studies are exploring the efficacy and safety of a single dose in $\mathrm{AD}$ as well as in asthma and other allergic disorders.

Another approach to target inflammatory infiltration is to block the emigration of activated T cells from lymphatic sites and the migration of epidermal DCs to the lymph nodes. This goal can be reached by modulation of their receptors for sphingosine 1-phosphate (S1P), the active terminal derivative of sphingosine metabolism. S1P acts via gradients in circulatory fluids and has been reported to be increased in various conditions such as multiple sclerosis and neurodegeneration ${ }^{158}$, pneumonia ${ }^{159}$, psoriasis $^{160}$, asthma ${ }^{161}$ and more recently in $\mathrm{AD}^{162}$. The multiple biological activities of S1P are mediated by five distinct $G$ protein-coupled receptors (S1PR1-5), which are differently expressed in various tissues $^{163}$. Whereas DCs express S1PR1, S1PR3 and S1PR4, T cells display S1PR1 and S1PR4 (REFS ${ }^{164-166}$ ) and represent ideal targets for compounds able to modulate their expression on immune cells and thereby prevent lymphocyte migration from lymphatic tissue and reduce the pool of peripheral lymphocytes able to migrate into inflammatory tissues without broad immunosuppression. This strategy has been successfully developed with the S1PR1,3-5 agonist fingolimod ${ }^{167}$ and the S1PR1,5 agonist siponimod ${ }^{168}$, which are both approved for the therapy of multiple sclerosis. Although they act initially as S1PR agonists, they promote receptor internalization and so are functional antagonists in the longer term.

Etrasimod (APD334) is a next-generation S1PR agonist that induces sustained internalization of the S1PR1 receptor. In the phase IIb ADVISE trial, etrasimod achieved the primary end point validated IGA (vIGA) $0 / 1$ in $36.8 \%$ versus $13 \%$ in the placebo group. Of note, the study included a high proportion of patients with a moderate form of AD. As soon as at week 4, significant changes in peak pruritus NRS (PP-NRS) and the secondary end point EASI75 were observed (see press statement in Related links). Interestingly, the drug did not induce adverse events such as cardiovascular toxicity commonly seen with this class of compound. Etrasimod was overall well tolerated, opening the door for the phase III programme. SCD-044, LC51-0255, BMS-986166 and KT-474 are other selective S1PR1 agonists that aim to affect lymphocyte trafficking and are currently in development for $\mathrm{AD}$ and/or psoriasis and other autoimmune disorders.

For dermatological disorders such as $\mathrm{AD}$, compounds of molecular weight $<500$ Dalton, optimally and stably formulated in a cream or ointment basis, can potentially penetrate the epidermal barrier and directly act on cutaneous inflammation. The topical application of the prototypical S1PR agonist fingolimod (mol. wt 343) has been reported to reduce allergic inflammation in animal models of skin disorders ${ }^{169-171}$. With its molecular weight of 443.5, the highly selective S1PR1 agonist AKP-11 has entered clinical development in dermatology as a topical formulation for psoriasis and $\mathrm{AD}$ with the potential to be a first-in-class S1PR1 modulator in these indications. Although the phase I trial generated promising results for psoriasis, no reports are currently available with regard to its use in $\mathrm{AD}$. Besides the major impact on the segregation of $\mathrm{T}$ cells, the biological activity of S1P and its receptors on innate immunity ${ }^{172}$, epidermal keratinocytes ${ }^{173-176}$ and on DCs ${ }^{177-179}$ remain interesting elements to be considered in explaining the mode of action of this class of compounds in $\mathrm{AD}$.

\section{Targeting the key symptom: itch-scratch cycle}

The mechanisms that underlie itching sensation are complex, involving multiple mediators that initiate the activation of peripheral sensory neurons. They offer a number of potential targets for pharmacological intervention ${ }^{29,180-182}$. As neurons express receptors for IL-4 and IL-13, the early improvement of itch upon targeted therapy with dupilumab, tralokinumab or lebrikizumab supports the assumption of a direct effect of these drugs on nerve endings ${ }^{92,96,183}$.

IL-31 is a prominent pruritogenic cytokine produced by infiltrating $\mathrm{T}_{\mathrm{H}} 2$ cells in $\mathrm{AD}$ and correlates with disease severity ${ }^{97,184,185}$. It signals through the heterodimerization of IL-31R $\alpha$ and the oncostatin M receptor- $\beta$ $(\mathrm{OSMR} \beta)^{186,187}$. Targeting IL-31 and its receptor is a focus of strategies to better control itching ${ }^{188}$. In a phase IIa study, the anti-IL-31R $\alpha$ antibody nemolizumab led to a significant decrease in the pruritus sensation, but the overall clinical inflammation as evaluated by the body surface area (BSA), EASI and IGA scorings did not improve significantly at this time point ${ }^{189}$. In the 52-week long-term extension of this study, the efficacy towards itching was confirmed while achieving clinical improvement in a dose-independent fashion ${ }^{190}$. However, the concomitant use of TCSs and the lack of placebo arm in this extension study makes the interpretation challenging. In another phase II study, the expected early improvement in itching was captured 
by the decrease in PP-NRS (69\% versus 34\%). IGA 0/1 was reached in $33 \%$ of the patients versus $12 \%$ in the placebo group at week 16 but not at later time points, presumably owing to large background consumption of TCS $^{191}$. The overall efficacy in pruritus in combination with TCSs was further confirmed in a phase III study over 16 weeks with a decrease of $43 \%$ versus $21 \%$ in the placebo group as measured by the visual analogue scale score. The EASI score showed a moderate improvement of $46 \%$ with nemolizumab versus $33 \%$ in the placebo group $^{192}$. Of note, nemolizumab generated promising results in prurigo nodularis, a highly pruritic skin disorder assumed to be related to $\mathrm{AD}^{193}$.

Vixarelimab (KPL-716) is a fully human antibody that targets the other receptor subunit for IL-31, OSMR $\beta$. In a repeated-single-dose phase Ib study over 12 weeks in $\mathrm{AD}$, vixarelimab induced a rapid and sustained reduction in pruritus with $53 \%$ of the patients having a $>4$-point reduction in the pruritus score versus $26 \%$ in the placebo group. However, there was no significant effect on EASI and SCORAD ${ }^{194}$.

Substance $\mathrm{P}$ is involved in the initiation and transmission of itch through the neurokinin 1 receptor $(\mathrm{NK} 1 \mathrm{R})^{195,196}$ and the Mas-related G protein-coupled receptor (MRGPRS) ${ }^{197,198}$ expressed in the central nervous system and on various other cell types. Overexpression of substance $\mathrm{P}$ and NK1R induces itching skin disorders including $\mathrm{AD}^{199-202}$, suggesting that this signalling pathway could be pharmacologically targeted to control itching sensation and neurogenic inflammation ${ }^{203,204}$. Serlopitant is a NK1R antagonist that has shown efficacy in reducing pruritus in a phase II study in patients with treatment-refractory prurigo nodularis ${ }^{205}$. However, in another large phase II study (ATOMIK study; 484 participants) and in patients with $\mathrm{AD}$, the drug missed the primary end point of change in worst itch NRS from baseline (NCT02975206). In a phase III study with 375 patients, another novel NK1R antagonist tradipitant (VLY-686) (EPIONE study), missed the primary end point of reduction in pruritus. However, reduction of $50 \%$ in SCORAD from baseline was noticed in mild forms of $\mathrm{AD}^{206}$.

The P2X purinoreceptors 3 (P2XR3) are cation channels expressed in sensory neurons that are activated by extracellular ATP and exert an important role in peripheral irritation, pain sensation, coughing but potentially also in itch ${ }^{207-209}$. The selective P2X3 antagonist BLU5937 is in development to treat chronic cough and pruritus. A phase IIa study (the BLUEPRINT trial) has recently been initiated to explore the effect of this drug on pruritus in patients suffering from $\mathrm{AD}$. The topline results are expected by the end of 2021 .

Current data obtained from trials of drugs targeting either $\mathrm{T}_{\mathrm{H}} 2$ inflammation (such as dupilumab) or more specifically the pruritus in $\mathrm{AD}$ may help to provide a temporary answer to one of the most debated questions in $\mathrm{AD}$ research: is it the itch that rashes or the rash that itches? Currently available data suggest that in $\mathrm{AD}$, itching is a result of inflammation. However, this conclusion may not be generalized for a number of itchy skin disorders such as prurigo nodularis in which targeting itch remains promising ${ }^{193,205,210-212}$.

\section{The broad approach with JAK inhibitors}

The JAK family of tyrosine kinases includes four members: JAK1, JAK2, JAK3 and tyrosine kinase 2 (TYK2) ${ }^{213}$. Depending on their dose-dependent selectivity for one or several JAKs, the JAK inhibitors (JAKi) exert a broad immunopharmacological impact because they block the signal transduction pathways of multiple type I (haematopoietic family) and type II (interferon) cytokine receptors $^{17,214}$. These include heterodimeric receptors involved in distinct types of immune response but also colony-stimulating factor and hormone receptors. Currently, there are more than 90 patented JAKi, many of which are in clinical development for various indications such as rheumatoid arthritis and inflammatory bowel diseases ${ }^{17,215,216}$. Recently, JAKi were used successfully in treating the cytokine storm generated by the SARS-CoV-2 virus ${ }^{217}$. As the receptors for $\mathrm{T}_{\mathrm{H}} 2$ and $\mathrm{T}_{\mathrm{H}} 22$ cytokines involve downstream JAK-STAT signalling, JAKi represent interesting compounds for the therapy of $\mathrm{AD}$.

With regard to their respective selectivity, JAKi approved for $\mathrm{AD}$ or in clinical development for this indication can be classified into three main categories: the non-selective (pan-)JAKi (delgocitinib, cerdulatinib, jaktinib, CEE321); the dual inhibitors (baricitinib, ruxolitinib, brepocitinib, ATI-1777); and the selective JAK1 inhibitors (upadacitinib, abrocitinib, SHR0302). Besides psoriasis and psoriatic arthritis, alopecia areata and vitiligo ${ }^{218}, \mathrm{AD}$ is the major dermatological indication for topical and systemic JAKi ${ }^{219,220}$.

Topical JAK inhibitors. Delgocitinib (JTE-052/LEO 242549) is a first-generation, non-selective JAK inhibitor that, upon topical and oral application, was shown to improve allergic contact sensitization and $\mathrm{AD}$-like inflammation in animal models ${ }^{221-223}$. After successful phase III studies ${ }^{224,225}$, topical delgocitinib ointment was approved in 2020 for moderate to severe AD in Japan ${ }^{226}$. While its clinical development in a cream basis (LEO 24249) has been suspended in the USA and the EU, the development of this product is being focused on chronic hand eczema ${ }^{227}$.

Owing to its particular activity against all JAKs and the spleen tyrosine kinase (SYK), cerdulatinib was initially developed as a systemic therapy for haematological malignancies ${ }^{228}$. Besides T cell activation, SYK is a crucial signalling molecule for the high-affinity receptor for IgE (FceRI) expressed on epidermal Langerhans cells and inflammatory dendritic epidermal cells ${ }^{229-231}$. Therefore, simultaneous targeting of JAKs and SYK by cerdulatinib appears to be an appealing strategy for topical pharmacological intervention in $\mathrm{AD}$. In a phase $\mathrm{Ib}$ study with cerdulatinib gel in mild to moderate $\mathrm{AD}$, the compound significantly reduced epidermal thickness, decreased inflammatory DCs and strongly impacted on the inflammatory signature in the transcriptomic analysis $^{232}$. The mean change in EASI score as well as significantly decreased itch show that cerdulatinib could be a promising alternative to TCSs and topical calcineurin inhibitors.

Ruxolitinib is a dual JAK1/JAK2 inhibitor that has advanced in the phase III programme (TRuE AD1 and 
AD2 studies) as a cream for mild to moderate forms of $\mathrm{AD}$. In a phase II study, this compound provided a significant therapeutic benefit with $72 \%$ change (16\% for placebo) from baseline of EASI and an IGA $0 / 1$ of $38 \%$ versus $8 \%$ in the placebo group ${ }^{233}$. As a common feature of all JAKi, there was a rapid (within $36 \mathrm{~h}$ ) and sustained reduction in the itch sensation. Interestingly, ruxolitinib also has potential for vitiligo ${ }^{218}$ and for cutaneous lupus ${ }^{234}$.

The other topical JAKi, that is, brepocitinib (JAK1/ TYK2), jaktinib (pan-JAKi), ATI-1777 (JAK1/JAK3), CEE321 (pan-JAKi) and SHR0302 (JAK1) are currently in clinical development (TABLE 1) and results are not yet available.

Systemic JAK inhibitors. Baricitinib is a first-in-class oral JAK inhibitor directed against JAK1/JAK2 approved in the EU in 2020 for adult patients with moderate to severe $\mathrm{AD}$. In this population, the primary end point IGA $0 / 1$ was reached in $17 \%$ versus $5 \%$ for placebo (BREEZEAD1 study) and $14 \%$ versus $5 \%$ in the placebo group (BREEZE-AD2 study) ${ }^{235}$. With regard to the onset of action on itch, most patients reported a significant improvement within a few days as shown by PP-NRS. In a pooled safety analysis of the cumulative data from eight studies with 2,531 patients $(2,247$ patient-years with median duration of 310 days) there were no signals for serious or opportunistic infections ${ }^{236}$. Viral infections such as herpes simplex and eczema herpeticum as well as headache were more frequent than in the placebo group, and there were only two venous thrombosis events reported. Interestingly, unlike selective JAKi (see below), there was no increase in acne under baricitinib. The paediatric programme is currently ongoing.

Signalling of receptors for factors involved in haematopoiesis, such as GM-CSF, G-CSF, EPO or leptin, is crucially dependent on JAK2 homodimers. Thus, the quest for JAK1-selective compounds resulted in the development of second-generation inhibitors such as upadacitinib and abrocitinib ${ }^{17}$, for which the regulatory approvals are expected before the end of 2021. Of note, the JAK1-selective inhibitor SHR0302 is currently in development as a topical application for mild-to-moderate forms as well as for oral application for moderate-to-severe forms of $\mathrm{AD}$. In their respective phase III programmes, upadacitinib (approved since 2019 for rheumatoid arthritis) and abrocitinib demonstrated significant improvement in severity and pruritus as well as in patient-related outcomes (PROs). In the monotherapy pivotal trials (Measure Up 1 and 2), upadacitinib showed significant results at week 16 for the primary end point IGA $0 / 1\left(\right.$ REF. $\left.^{237}\right)$, along with an early reduction in pruritus and improvement of 4 or more points in the PP-NRS score at week 16 . The safety profile was comparable to that seen in patients with rheumatoid arthritis with this compound. Acne, upper respiratory tract infections and nasopharyngitis were the most common treatment-emergent adverse events. The other JAK1-selective JAKi abrocitinib showed similar significant results in phase $\mathrm{III}^{238}$ studies. In the pivotal monotherapy studies (JADE-MONO-1 and JADE-MONO-2), the primary end point IGA 0/1 was reached. A recent comparative study of abrocitinib with dupilumab and placebo, confirmed that abrocitinib and dupilumab were significantly more efficacious than placebo. Abrocitinib was superior to dupilumab in itch response after 2 weeks but not for other secondary end points. For both abrocitinib and upadacitinib, the rates of discontinuation in the phase III trials owing to an adverse event were lower than in the placebo groups. As AD is the most common inflammatory skin disorder in children, the compounds may be of particular interest for the severe forms in this population and data from the ongoing paediatric programmes are eagerly awaited.

In terms of efficacy, JAKi have the potential to become game changers in the standard of care for some patients with $\mathrm{AD}$, and their benefit-risk ratio in the $\mathrm{AD}$ population seems acceptable. As JAK2 is linked to the receptors of cytokines assumed to be instrumental in $\mathrm{AD}$ such as IL-13, IL-22, IL-5 and IL-31, one would assume that blocking JAK2 would provide added value in terms of efficacy compared with the more specific JAK1 inhibitors. However, the phase III data of the dual JAK1/JAK2 inhibitor baricitinib suggest a lower efficacy than the more JAK1-specific inhibitors abrocitinib and upadacitinib. A number of mutually non-excluding explanations can be discussed at this current stage of knowledge: owing to the overall tissue inflammatory burden expected in moderate to severe forms of $\mathrm{AD}$ where almost the complete skin surface is affected, the JAK1/JAK2 inhibitor baricitinib is underdosed compared with rheumatoid arthritis where the burden of the inflammatory reaction on the joints is more limited and the drug is not taken as a monotherapy but in combination with other anti-inflammatory compounds. Another possible explanation for this discrepancy could be related to the inhibition of the biological activity of the JAK2-associated receptor for IL-10, a well-recognized cytokine with anti-inflammatory properties and a key mediator in tolerance induction. With regard to the long-term safety of dual inhibitors, the latter aspect may also be of relevance in the context of mechanisms involved in antitumour defence. A direct extrapolation from the short- and long-term safety data in rheumatoid arthritis and other disorders where JAKi have been used so far should be considered with caution, since the target populations are different, that is, patients with rheumatoid arthritis are older than patients with $\mathrm{AD}$, they may have additional comorbidities requiring multiple other medications and therefore have a higher risk of drug-drug interactions. At this stage of development of topical and oral JAKi, the number of patients and the data related to extended drug exposure remain limited. It is not yet clear whether, for comparable efficacy, JAK1 inhibitors display distinct safety profiles between themselves and compared with dual inhibitors. Comparative safety analysis extracted from post-authorization safety studies and/or real-world registries will be key to fully evaluate the safety profile of the different JAKi in $\mathrm{AD}$.

\section{Other inhibitors}

Another approach to affect inflammation is to inhibit the tropomyosin receptor kinases (TRKs), which bind neurotrophins known to aggravate skin inflammation ${ }^{239}$. 
Table 1 | Current therapeutic pipeline for atopic dermatitis

\begin{tabular}{|c|c|c|c|c|c|}
\hline Strategy & $\begin{array}{l}\text { Drug type } \\
\text { and mode of } \\
\text { application }\end{array}$ & Agent/company & Mode of action/target & $\begin{array}{l}\text { Clinical development } \\
\text { phase in atopic } \\
\text { dermatitis }\end{array}$ & Clinical trial ID \\
\hline \multirow{7}{*}{$\begin{array}{l}\text { Modulating } \\
\text { the } \\
\text { microbiome }\end{array}$} & \multirow{3}{*}{$\begin{array}{l}\text { Bacterial } \\
\text { strains } \\
\text { - topical }\end{array}$} & B244 (AOBiome) & Nitric oxide donor & Illb & NCT04490109 \\
\hline & & ShA9 (NIAID) & $\begin{array}{l}\text { Targeted microbiome } \\
\text { transplant }\end{array}$ & $\mathrm{l} / \mathrm{Ila}$ & NCT03151148 \\
\hline & & FB-401 (Forte Biosciences) & $\begin{array}{l}\text { Bacterial replacement, } \\
\text { anti-inflammation via TLR5 } \\
\text { and TNFR activation }\end{array}$ & Illb & NCT04504279 \\
\hline & \multirow{2}{*}{$\begin{array}{l}\text { Small } \\
\text { molecule } \\
\text { - topical }\end{array}$} & $\begin{array}{l}\text { CLS-001/omiganan (Cutaneous Life } \\
\text { Sciences) }\end{array}$ & Cell membrane enhancer & ॥ & NCT02456480 \\
\hline & & $\begin{array}{l}\text { ATx201/niclosamide (Union } \\
\text { Therapeutics) }\end{array}$ & Protonophore activity & $\|$ & NCT04339985 \\
\hline & \multirow[t]{2}{*}{$\begin{array}{l}\text { Bacterial } \\
\text { strains - oral }\end{array}$} & EDP1815 (Evelo) & $\begin{array}{l}\text { Modulation of systemic } \\
\text { inflammation }\end{array}$ & $\mathrm{lb}$ & NCT03733353 \\
\hline & & STMC-103H (Siolta therapeutics) & $\begin{array}{l}\text { Immunomodulation via } \\
\text { microbiome manipulation }\end{array}$ & $\mathrm{lb}$ & NCT03819881 \\
\hline \multirow{8}{*}{$\begin{array}{l}\text { Targeting } \\
\text { the innate } \\
\text { immune } \\
\text { response }\end{array}$} & $\begin{array}{l}\text { Small } \\
\text { molecule } \\
\text { - topical }\end{array}$ & Tapinarof/benvitimod (Dermavant) & AhR agonist & $\mathrm{llb}$ & NA \\
\hline & \multirow{7}{*}{$\begin{array}{l}\text { Biologic } \\
\text { - injection }\end{array}$} & Tezepelumab (Amgen/AstraZeneca) & TSLP & Ila & NCT02525094 \\
\hline & & Etokimab (AnaptysBio) & IL-33 & Ila & NCT03533751 \\
\hline & & REGN3500 (Regeneron) & IL-33 & Ila & NCT03738423 \\
\hline & & Astegolimab (Genentech) & IL-33 & Ila & NCT03747575 \\
\hline & & MEDI3506 (Medlmmune) & IL-33 & Ila & NCT04212169 \\
\hline & & Bermekimab (Janssen) & IL-1a & Ila & NCT03496974 \\
\hline & & Spesolimab (Böhringer Ingelheim) & IL-36R & Ila & NCT03822832 \\
\hline \multirow{17}{*}{$\begin{array}{l}\text { Targeting } \\
\text { the } \\
\text { adaptive } \\
\text { immune } \\
\text { response }\end{array}$} & \multirow[t]{17}{*}{$\begin{array}{l}\text { Biologic } \\
\text { — injection }\end{array}$} & $\begin{array}{l}\text { GBR 830/ISB } 830 \text { (Glenmark/ } \\
\text { Ichnos) }\end{array}$ & OX40 & Illb & NCT03568162 \\
\hline & & KHK4083 (Kyrin) & OX40 & $\mathrm{Ilb}$ & NCT03703102 \\
\hline & & KY1005 (Kymab/Sanofi) & OX40L & Ila & NCT03754309 \\
\hline & & Dupilumab (Regeneron/Sanofi) & IL-4Ra & $\begin{array}{l}\text { Approved globally, } \\
\text { staggered paediatric } \\
\text { programme ongoing }\end{array}$ & NCT03346434 \\
\hline & & CBP-201 (Connect Biopharma) & IL-4Ra & $\mathrm{Ilb}$ & NCT04444752 \\
\hline & & AK120 (Akesobio) & IL-4Ra & $\mathrm{lb}$ & NCT04256174 \\
\hline & & ASLAN004 (ASLAN) & IL-13Ra1 & $\mathrm{lb}$ & NCT04090229 \\
\hline & & Tralokinumab (LEO Pharma) & IL-13 & $\begin{array}{l}\text { Approved in EU, } \\
\text { staggered paediatric } \\
\text { programme ongoing }\end{array}$ & NCT03526861 \\
\hline & & Lebrikizumab (Allmiral/Lilly) & IL-13 & $\begin{array}{l}\text { III, staggered paediatric } \\
\text { programme ongoing }\end{array}$ & NCT04250350 \\
\hline & & Benralizumab (AstraZeneca) & IL-5Ra & II & NCT04605094 \\
\hline & & Omalizumab (Novartis) & $\lg E$ & II & NCT02300701 \\
\hline & & $\begin{array}{l}\text { FB825/anti-CemX (LEO Pharma/ } \\
\text { Oneness Biotech) }\end{array}$ & $\mathrm{mlg} E$ & Ila & NCT04413942 \\
\hline & & Fezakinumab (IIT) & IL-22 & Ila & NCT01941537 \\
\hline & & LEO 138559 (LEO Pharma) & IL-22R1 & $\mathrm{lb}$ & NCT03514511 \\
\hline & & Secukinumab (Novartis) & IL-17A & Ila & $\begin{array}{l}\text { NCT02594098, } \\
\text { NCT03568136 }\end{array}$ \\
\hline & & Risankizumab (AbbVie) & IL-23 & Ila & NCT03706040 \\
\hline & & LY3471851 (Lilly) & rhlL-2 to $T_{\text {req }}$ cells & $\mathrm{lb}$ & NCT04081350 \\
\hline
\end{tabular}


Table 1 (cont.) | Current therapeutic pipeline for atopic dermatitis

\begin{tabular}{|c|c|c|c|c|c|}
\hline Strategy & $\begin{array}{l}\text { Drug type } \\
\text { and mode of } \\
\text { application }\end{array}$ & Agent/company & Mode of action/target & $\begin{array}{l}\text { Clinical development } \\
\text { phase in atopic } \\
\text { dermatitis }\end{array}$ & Clinical trial ID \\
\hline \multirow{20}{*}{$\begin{array}{l}\text { Targeting } \\
\text { the } \\
\text { adaptive } \\
\text { immune } \\
\text { response } \\
\text { (cont.) }\end{array}$} & \multirow{8}{*}{$\begin{array}{l}\text { Small } \\
\text { molecule } \\
\text { - oral }\end{array}$} & Adriforant (Novartis) & $\mathrm{H} 4 \mathrm{R}$ & Ilb & NCT03517566 \\
\hline & & LEO 152020/JW1601 (LEO Pharma) & $\mathrm{H} 4 \mathrm{R}$ & 1 & NCT04203836 \\
\hline & & RPT193 (RAPT Therapeutics) & CCR4 & Ila & NCT04271514 \\
\hline & & Etrasimod (Arena Pharma) & S1PR1, S1PR4, S1PR5 & Ilb & NCT04162769 \\
\hline & & SCD-044 (Sun Pharma) & S1PR1 & Ila & NCT04684485 \\
\hline & & LC51-0255 (LG Chem) & S1PR1 & 1 & NA \\
\hline & & BMS-986166 (Bristol Myers Squibb) & S1PR1 & Ila & NCT03038711 \\
\hline & & KT-474 (Kymera) & S1PR1 & $\mathrm{lb}$ & NCT04772885 \\
\hline & \multirow{12}{*}{$\begin{array}{l}\text { Small } \\
\text { molecule } \\
\text { - topical }\end{array}$} & AKP-19 (Akaal Pharma) & S1PR1 & II & NA \\
\hline & & $\begin{array}{l}\text { Lotamilast (RVT-501 /E6005) } \\
\text { (Dermavant) }\end{array}$ & PDE4 & II & $\begin{array}{l}\text { NCT03394677, } \\
\text { NCT02950922 }\end{array}$ \\
\hline & & $\begin{array}{l}\text { Difamilast (OPA-15406/MM36) } \\
\text { (Otsuka) }\end{array}$ & PDE4 & II & NCT02945657 \\
\hline & & DRM02 (Dermira) & PDE4 & II & NCT01993420 \\
\hline & & LEO 29102 (LEO Pharma) & PDE4 & II & NCT01037881 \\
\hline & & Roflumilast (AstraZeneca) & PDE4 & $\begin{array}{l}\text { II; pharmacokinetics } \\
\text { and efficacy in } \\
\text { paediatrics }\end{array}$ & NCT04156191 \\
\hline & & $\begin{array}{l}\text { Hemay-808 (Tianjin Hemay } \\
\text { Pharmaceutical) }\end{array}$ & PDE4 & II & NCT04352595 \\
\hline & & PF-07038124 (Pfizer) & PDE4 & II & NCT04664153 \\
\hline & & BEN2293 (BenevolentiAl) & TRK & I/II & NCT04737304 \\
\hline & & HY209 (Shaperon) & GPCR19 & Ila & NCT04530643 \\
\hline & & VTP-38543 (Vitae Pharma) & Liver $\mathrm{X}$ receptor- $\beta$ & $\mathrm{I} / \mathrm{II}$ & NCT02655679 \\
\hline & & ALX 101 (Ralexar) & Liver X receptor & II & NCT03859986 \\
\hline \multirow[t]{5}{*}{$\begin{array}{l}\text { Targeting } \\
\text { itching }\end{array}$} & \multirow[t]{2}{*}{$\begin{array}{l}\text { Biologic } \\
\text { - injection }\end{array}$} & Nemolizumab (Galderma) & IL-31 & III & $\begin{array}{l}\text { NCT03989349, } \\
\text { NCT03985943 }\end{array}$ \\
\hline & & Vixarelimab (Kiniksa Pharma) & OSMR $\beta$ & $\mathrm{Ila} / \mathrm{b}$ & NCT03816891 \\
\hline & \multirow{3}{*}{$\begin{array}{l}\text { Small } \\
\text { molecule } \\
\text { - oral }\end{array}$} & Serlopitant (Menlo) & NK1R & II & NCT02975206 \\
\hline & & Tradipitant (Vanda) & NK1R & II & NCT03568331 \\
\hline & & BLU-5937 (Bellus) & $\mathrm{P} 2 \mathrm{X} 3$ & II & NCT04693195 \\
\hline \multirow{12}{*}{$\begin{array}{l}\text { Inhibiting } \\
\text { Janus } \\
\text { kinases }\end{array}$} & \multirow{8}{*}{$\begin{array}{l}\text { Small } \\
\text { molecule } \\
\text { - topical }\end{array}$} & Delgocitinib (Japan Tobacco/LEO) & Pan-JAK & $\begin{array}{l}\text { Ilb in EU, approved in } \\
\text { Japan }\end{array}$ & NCT03725722 \\
\hline & & Ruxolitinib (Incyte) & JAK1/JAK2 & III & $\begin{array}{l}\text { NCT03745638, } \\
\text { NCT03745651 }\end{array}$ \\
\hline & & $\begin{array}{l}\text { Cerdulatinib (RVT/DMVT502) } \\
\text { (Dermavant) }\end{array}$ & Pan-JAK/SYK & $\mathrm{lb}$ & NA \\
\hline & & Brepocitinib (Pfizer) & JAK1/TYK2 & $\mathrm{llb}$ & NCT03903822 \\
\hline & & ATI-1777 (Aclaris) & JAK1/JAK3 & II & NCT04598269 \\
\hline & & CEE321 (Novartis) & Pan-JAK & 1 & NCT04612062 \\
\hline & & Jaktinib (Suzhou Zeigen Biopharma) & Pan-JAK & Ila & NCT04539639 \\
\hline & & SHR0302 (Reistone Biopharma) & JAK1 & II & NCT04717310 \\
\hline & \multirow[t]{4}{*}{$\begin{array}{l}\text { Small } \\
\text { molecule } \\
\text { - oral }\end{array}$} & Baricitinib (Lilly) & JAK1/JAK2 & $\begin{array}{l}\text { Approved in EU for } \\
\text { adults, staggered } \\
\text { paediatric programme } \\
\text { ongoing }\end{array}$ & NCT03952559 \\
\hline & & Upadacitinib (AbbVie) & JAK1 & $\begin{array}{l}\text { III, staggered paediatric } \\
\text { programme ongoing }\end{array}$ & NCT03646604 \\
\hline & & Abrocitinib (Pfizer) & JAK1 & $\begin{array}{l}\text { III, staggered paediatric } \\
\text { programme ongoing }\end{array}$ & NCT03627767 \\
\hline & & SHR0302 (Reistone Biopharma) & JAK1 & II & NCT04162899 \\
\hline
\end{tabular}

AhR, aryl-hydrocarbon receptor; BTK, Bruton tyrosine kinase; CCR4, C-C chemokine receptor 4; GPCR19, G protein-coupled receptor 19; H4R, type 4 histamine receptor; IL-4Ra, $\alpha$-chain of the IL-4 receptor; IL-5Ra, a-chain of the IL-5 receptor; IL-13Ra1, $\alpha 1$ chain of the IL-13 receptor; IL-22R1, IL-22 receptor 1; JAK, Janus kinase; NK1R, neurokinin 1 receptor; NA, not applicable; OSMR $\beta$, oncostatin M receptor- $\beta$; OX40L, OX40 ligand; PDE4, phosphodiesterase 4; P2X3, purinoreceptor 3; rhIL-2, recombinant human IL-2; S1PR1, sphingosine 1-phosphate receptor $1 ; \mathrm{T}_{\text {reg }}$ cell, regulatory T cell; TRK, tropomyosin receptor kinase; TSLP, thymic stromal lymphopoietin. 
A topical gel formulation of the TRK inhibitor BEN2293 has been developed and is currently in a phase I/II proof-of-concept study for mild to moderate forms of $\mathrm{AD}$.

Taureoxycholic acid (HY209) is an agonist of $\mathrm{G}$ protein-coupled receptor 19. In an animal model of $\mathrm{AD}$, HY209 reduced $\mathrm{T}_{\mathrm{H}} 2$ inflammation via inhibition of nuclear factor $\kappa \mathrm{B}(\mathrm{NF}-\kappa \mathrm{B})$ and $\mathrm{p} 38$ kinase. Typical biomarkers of AD such as TSLP and CCL17/TARC were also significantly decreased, as was serum $\operatorname{IgE}^{240}$. HY209 is considered an interesting compound for the therapy of $\mathrm{AD}$ and is currently being tested in a phase II trial using a topical gel formulation.

$\mathrm{AD}$ is characterized by a disturbed epidermal barrier and chronic inflammation. Interestingly, liver $\mathrm{X}$ receptors (LXR $\alpha$ and LXR $\beta$ ) are ligand-activated nuclear transcription factors that are involved in the regulation of epidermal barrier function and exhibit suppressive effects on skin inflammation ${ }^{241,242}$, and are therefore potential targets for pharmacological intervention in $\mathrm{AD}$. A comparative transcriptomic analysis of skin biopsy samples from a phase I/II study using a topical cream formulation including the penetration enhancer TranscutolP and the LXR $\beta$ agonist VTP38543 (in patients with mild to moderate AD), revealed increased mRNA expression of important epidermal structural proteins (loricrin and filaggrin) as well as improvement of epidermal hyperplasia. However, the compound did not significantly downregulate markers of inflammation. Although the drug was well tolerated (primary end point reached: number of patients with treatment-related adverse events), the results in terms of clinical improvement (secondary end points) assessed by percentage change in body surface area, percentage change in SCORAD and EASI, were not promising. Moreover, the effects observed were not dose-dependent (NCT02655679). ALX 101 is another LXR $\beta$ agonist currently being tested in a phase IIb study using a gel formulation in patients with moderate AD. Results are not yet available.

\section{Towards precision medicine for AD Scientific rationale}

New and broadly effective compounds such as JAKi have exhibited unprecedented efficacy. However, although patients expect that such new compounds provide full clinical response in a monotherapy regimen, the phase III trials with these compounds have highlighted the variability of the clinical response. Clearly, as for rheumatoid arthritis, JAKi are not the 'one-size-fits-all' approach for AD. This is certainly the case for the JAK1/JAK2 inhibitor baricitinib, for which the identification of the good-responder population is an unmet need. Patients have high expectations with regard to efficacy, and physicians aim to prescribe therapies for long-term control of the disorder. Although AD is not life-threatening, it has a profound impact on patient quality of life and that of their relatives. The steadily increasing number of new drugs in development for $\mathrm{AD}$ has indicated the potential for precision medicine to generate an optimized benefit-risk ratio, particularly in age ranges where safety issues are of crucial interest such as in paediatric patients, as well as in the elderly, where drug-drug interactions represent another potential threat.

There are multiple factors that contribute to the high heterogeneity of the age of disease onset in patients with $\mathrm{AD}$, the variations in the clinical phenotype (particularly in different ethnic backgrounds) and the different risks for early development of an 'atopic march' with atopic comorbidities (that is, allergic rhinitis and asthma), neuropsychiatric comorbidities (anxiety, depression) or later non-atopic comorbidities (cardiovascular disorders). These factors, which include diverse environmental influences, a complex genotype, microbiome-derived signals and a dynamic immune response, also underlie the highly variable therapeutic response and adverse events to established and new compounds for $\mathrm{AD}$ therapy ${ }^{243}$. Lessons from the history of previous drug development programmes in patient populations with complex phenotypes (for example, trastuzumab in breast cancer or mepolizumab in allergic asthma) have shown that compounds that failed to meet the primary end points in phase II or phase III studies in the classic one-size-fits-all approach may still be promising candidates in certain subgroups of patients. This is probably relevant for $\mathrm{AD}^{243}$, in which phenotype and/or endotype-based stratification for selection of potential treatment responders with an optimal risk-benefit ratio represents an attractive strategy.

A better understanding of the biochemical and functional consequences of the genetically driven epidermal barrier dysfunction would enable the design of new skin care products that are better adapted to address the individual needs of a patient, to correct and improve the sensitive and permeable skin in AD. An early precise determination of the genetic and/or environmental risk factors leading to the emergence of $\mathrm{AD}$ in infancy as well as the risk of developing an atopic march (that is, atopic comorbidities such as allergic asthma) bears the tremendous potential of a disease-modifying prevention strategy early in life ${ }^{244}$. The same holds true for the early identification of patients at risk of developing non-atopic comorbidities such as cardiovascular or neuropsychiatric disorders, offering unique opportunities for prevention and risk mitigation strategies.

\section{Strategies for implementation}

Understanding a complex disorder such as AD in its full phenotypic and mechanistic spectrum in order to apply a precision medicine approach is a challenging goal. It requires systematic analysis of a wide cohort of representative patients including all age and severity ranges ${ }^{245}$, ideally at a global level. To reach this ultimate goal, longitudinal 'regulatory grade' patient registries linked to high-quality biorepositories collecting microbiome, cellular and fluid blood samples as well as skin tissue and/or non-invasive tape-strip specimens are crucial. Such integrated technological platforms would allow the construction of a multidimensional model of the underlying mechanisms and facilitate the discovery of new drug targets more specifically adapted to the distinct phases of the epithelial events and the dynamic immune response. This systematic approach would 
also foster the identification, validation and regulatory qualification of predictive and prognostic biomarkers for innovative molecular taxonomy and companion diagnostics accompanying drug development programmes for tailored targeted therapeutics ${ }^{246-249}$.

\section{Outlook}

As the skin is easily accessible for local therapy, treatment guidelines historically evolved following the established dogma that topical anti-inflammatory therapy is prioritized for mild to moderate forms of $\mathrm{AD}$, while systemic approaches, potentially associated with a higher risk of adverse reactions, are reserved for moderate to severe cases. Progress in our understanding of the manifold epithelial and immunological pathways leading to $\mathrm{AD}$ has contributed to the discovery of a remarkable number of therapeutically interesting pathways and targets. Translational efforts to convert this knowledge into drug discovery have paved the way for an impressive number of preclinical and clinical development programmes. Consequently, there is now an expanding pipeline for the therapy of this complex disorder.

However, the current drug discovery and development strategies still follow the above-mentioned dogma, which may neglect potential preventive and therapeutic approaches. Besides considering solely the severity of disease, these alternative approaches could rely on stratification of the $\mathrm{AD}$ population according to other dimensions such as phenotypic information, for example, age, age of onset, duration of disease, ethnic background as well as endotypic hallmarks provided by validated biomarkers. Identification of the window of opportunity according to the age of the patients for intervention in the skin and gut microbiomes would allow a differential approach using the numerous compounds aimed at correcting the dysbiotic constellation in AD. Sticking to arbitrary cut-off points in the severity scales to define whether a patient deserves systemic therapy may lead to underestimation of the overall systemic impact of inflammation in the skin and a driving force for comorbidities. Thereby, undertreatment of some individuals at high risk of developing atopic and non-atopic comorbidities as well as the missed opportunity to prevent them by an adequate pharmacological intervention may be substantial.

An area that has an escalating impact on drug development in dermatology is the increasing influence of third-party payers, particularly the health technology assessment agencies in Europe and more recently countries such as Japan. Hence, cost-effectiveness and market access issues tend to become a new hurdle and threat for drug discovery by disincentivizing innovation and hampering patient access. For example, despite its approval by the EMA in March 2020, the topical PDE4 inhibitor crisaborole has never been launched in Europe. Although approved in Japan, the termination of the clinical development in Europe of the JAK inhibitor delgocitinib is another example of the deleterious impact of such cost-effectiveness considerations on innovative drug development. While market access aspects become an integral part of the clinical development strategies for pharmaceutical companies, cost-effectiveness should not be the only consideration for third-party payers when it comes to the evaluation of the added value of a new compound. Instead, real-world data and experience, the unmet needs from the patient's (with increased literacy) perspective and their advocacy efforts deserve more attention in this context.

In summary, a better understanding of the mechanisms underlying AD has illuminated both the complexity and the systemic impact of this disorder and supported the development of a comprehensive pipeline of new compounds for disease management. For systemic therapy, biologics with a slow but pathway-specific mode of action are now competing with small molecules such as JAKi with fast but broader activity. Although biologics may be more adapted for long-term control and potentially disease modification in $\mathrm{AD}$, JAKi provide rapid relief in pruritus and inflammation but, while well tolerated, their benefit-risk ratio remains a significant issue for pharmacovigilance. If applied early in the natural course of the disorder, some of these products even have the potential to be disease modifiers in that they could impact on the atopic march and other comorbidities.

\section{Published online 20 August 2021}

1. Weidinger, S. \& Novak, N. Atopic dermatitis. Lancet 387, 1109-1122 (2016).

2. Bieber, T. Atopic dermatitis. N. Engl. J. Med. $\mathbf{3 5 8}$ 1483-1494 (2008).

3. Silverberg, J. I. et al. Atopic dermatitis in the pediatric population: a cross-sectional, international epidemiologic study. Ann. Allergy Asthma Immunol. 126, 417-428 (2021).

4. Barbarot, S. et al. Epidemiology of atopic dermatitis in adults: results from an international survey. Allergy 73, 1284-1293 (2018).

5. Yew, Y. W., Thyssen, J. P. \& Silverberg, J. I. A systematic review and meta-analysis of the regional and age-related differences in atopic dermatitis clinical characteristics. J. Am. Acad. Dermatol. 80, 390-401 (2019).

State of the art review on the heterogeneity of the phenotype depending on the ethnic and regional background.

6. Birdi, G., Cooke, R. \& Knibb, R. C. Impact of atopic dermatitis on quality of life in adults: a systematic review and meta-analysis. Int. J. Dermatol. 59 e75-e91 (2020).

7. Eckert, L., Gupta, S., Gadkari, A., Mahajan, P. \& Gelfand, J. M. Burden of illness in adults with atopic dermatitis (AD): analysis of National Health and
Wellness Survey data from France, Germany, Italy, Spain and the U.K. J. Am. Acad. Dermatol. 81 187-195 (2019)

8. Silverberg, J. I. Public health burden and epidemiology of atopic dermatitis. Dermatol. Clin. 35 283-289 (2017)

9. Ariens, L. F. M. et al. Economic burden of adult patients with moderate to severe atopic dermatitis indicated for systemic treatment. Acta Derm. Venereol. 99, 762-768 (2019).

10. Silverberg, J. I. Comorbidities and the impact of atopic dermatitis. Ann. Allergy Asthma Immunol. 123 144-151 (2019).

11. Thyssen, J. P., Skov, L., Hamann, C. R., Gislason, G. H. ¿ Egeberg, A. Assessment of major comorbidities in adults with atopic dermatitis using the Charlson comorbidity index J. Am. Acad Dermatol 76 1088-1092 (2017).

12. Andersen, Y. M. F., Egeberg, A., Skov, L. \& Thyssen, J. P. Comorbidities of atopic dermatitis: beyond rhinitis and asthma. Curr. Dermatol. Rep. 6 , 35-41 (2017).

13. Silverberg, J. I. et al. Measurement properties of the hospital anxiety and depression scale used in atopic dermatitis in adults. J. Invest. Dermatol. 139 1388-1391 (2019).
14. Vestergaard, C., Wollenberg, A. \& Thyssen, J. P. European Task Force on Atopic Dermatitis (ETFAD) Position Paper: treatment of parental atopic dermatitis during preconception, pregnancy and lactation period. J. Eur. Acad. Dermatol. Venereol. 34 426-427 (2020).

15. Thyssen, J. P. et al. European Task Force on Atopic Dermatitis (ETFAD): treatment targets and treatable traits in atopic dermatitis. J. Eur. Acad. Dermatol. Venereol. 34, e839-e842 (2020).

16. Wu, J. \& Guttman-Yassky, E. Efficacy of biologics in atopic dermatitis. Expert Opin. Biol. Ther. 20 525-538 (2020).

17. Schwartz, D. M. et al. JAK inhibition as a therapeutic strategy for immune and inflammatory diseases. Nat. Rev. Drug Discov. 16, 843-862 (2017). Excellent review on the mode of action of JAK inhibitors.

18. Weidinger, S., Beck, L. A., Bieber, T., Kabashima, K. \& Irvine, A. D. Atopic dermatitis. Nat. Rev. Dis. Prim. 4, 1 (2018).

A key review paper on the current understanding of the pathophysiology of $A D$.

19. Paller, A. S., Kabashima, K. \& Bieber, T. Therapeutic pipeline for atopic dermatitis: end of the drought? J. Allergy Clin. Immunol. 140, 633-643 (2017). 
20. Gilles, S. et al. The role of environmental factors in allergy: a critical reappraisal. Exp. Dermatol. 27. 1193-1200 (2018)

21. Stefanovic, N., Flohr, C. \& Irvine, A. D. The exposome in atopic dermatitis. Allergy 75, 63-74 (2020).

22. Byrd, A. L., Belkaid, Y. \& Segre, J. A. The human skin microbiome. Nat. Rev. Microbiol. 16, 143-155 (2018).

23. Meisel, J. S. et al. Commensal microbiota modulate gene expression in the skin. Microbiome 6, 20 (2018).

24. Kong, H. H. et al. Temporal shifts in the skin microbiome associated with disease flares and treatment in children with atopic dermatitis. Genome Res. 22, 850-859 (2012).

25. Shi, B. et al. The skin microbiome is different in pediatric versus adult atopic dermatitis. J. Allergy Clin. Immunol. 138, 1233-1236 (2016). Study describing the microbiome in the different ages of patients with $A D$

26. Williams, M. R. et al. Quorum sensing between bacterial species on the skin protects against epidermal injury in atopic dermatitis. Sci. Transl Med. 11, eaat8329 (2019).

27. Kim, B. E. \& Leung, D. Y. Epidermal barrier in atopic dermatitis. Allergy Asthma Immunol. Res. 4, 12-16 (2012).

28. Rerknimitr, P., Otsuka, A., Nakashima, C. \& Kabashima, K. The etiopathogenesis of atopic dermatitis: barrier disruption, immunological derangement, and pruritus. Inflamm. Regen. 37, 14 (2017).

29. Mack, M. R. \& Kim, B. S. The itch-scratch cycle: a neuroimmune perspective. Trends Immunol. 39 980-991 (2018)

30. Marenholz, I. et al. Meta-analysis identifies seven susceptibility loci involved in the atopic march. Nat. Commun. 6, 8804 (2015).

31. Wollenberg, A. et al. Consensus-based European guidelines for treatment of atopic eczema (atopic dermatitis) in adults and children: part I. J. Eur. Acad. Dermatol. Venereol. 32, 657-682 (2018).

32. Wollenberg, A. et al. Consensus-based European guidelines for treatment of atopic eczema (atopic dermatitis) in adults and children: part II. J. Eur. Acad. Dermatol. Venereol. 32, 850-878 (2018).

33. Katayama, I. et al. Japanese guidelines for atopic dermatitis 2017. Allergol. Int. 66, 230-247 (2017).

34. Eichenfield, L. F. et al. Current guidelines for the evaluation and management of atopic dermatitis: a comparison of the Joint Task Force Practice Parameter and American Academy of Dermatology guidelines. J. Allergy Clin. Immunol. 139, S49-S57 (2017).

35. Wollenberg, A. et al. ETFAD/EADV Eczema Task Force 2020 Position Paper on diagnosis and treatment of atopic dermatitis in adults and children. J. Eur. Acad. Dermatol. Venereol. 34, 2717-2744 (2020).

36. Leshem, Y. A., Hajar, T., Hanifin, J. M. \& Simpson, E. L. What the Eczema Area and Severity Index score tells us about the severity of atopic dermatitis: an interpretability study. $\mathrm{Br}$. J. Dermatol. 172, 1353-1357 (2015) Key paper for the stratification of $A D$ according to severity

37. Maintz, L., Bieber, T., Bissonette, R. ¿ Jack, C. Measuring atopic dermatitis disease severity: can electronic tools benefit clinical care? J. Allergy Clin. Immunol. Pract. 9, 1473-1486 (2021) Comprehensive review on the specific tools measuring severity and PROs.

38. Harkins, C. P., Kong, H. H. \& Segre, J. A. Manipulating the human microbiome to manage disease. JAMA 323, 303-304 (2019).

39. Tham, E. H., Koh, E., Common, J. E. A. \& Hwang, I. Y. Biotherapeutic approaches in atopic dermatitis. Biotechnol. J. 15, e1900322 (2020).

40. Callewaert, C., Knodlseder, N., Karoglan, A., Guell, M. \& Paetzold, B. Skin microbiome transplantation and manipulation: current state of the art. Comput. Struct. Biotechnol. J. 19, 624-631 (2021).

Informative review on the strategies to impact on the skin microbiome.

41. Paller, A. S. et al. The microbiome in patients with atopic dermatitis. J. Allergy Clin. Immunol. 143, 26-35 (2019).

42. Myles, I. A. et al. Therapeutic responses to Roseomonas mucosa in atopic dermatitis may involve lipid-mediated TNF-related epithelial repair. Sci. Transl Med. 12, eaaz8631 (2020).

43. Nakatsuji, T. et al. Development of a human skin commensal microbe for bacteriotherapy of atopic dermatitis and use in a phase 1 randomized clinical trial. Nat. Med. 27, 700-709 (2021)

44. Guttman-Yassky, E. et al. ATx201 modulates biomarkers of skin barrier function and cutaneous inflammation in patients with moderate atopic dermatitis. J. Invest. Dermatol. 140, S77 (2020).

45. Cully, M. Microbiome therapeutics go small molecule. Nat. Rev. Drug Discov. 18, 569-572 (2019).

46. Zapotoczna, M. et al. Eradication of Staphylococcus aureus biofilm infections using synthetic antimicrobial peptides. J. Infect. Dis. 215, 975-983 (2017).

47. Czarnowicki, T. et al. Petrolatum: barrier repair and antimicrobial responses underlying this "inert" moisturizer. J. Allergy Clin. Immunol. 137, 1091-1102 (2016).

48. Simpson, E. L. et al. Emollient enhancement of the skin barrier from birth offers effective atopic dermatitis prevention. J. Allergy Clin. Immunol. 134, 818-823 (2014)

49. Horimukai, K. et al. Application of moisturizer to neonates prevents development of atopic dermatitis. J. Allergy Clin. Immunol. 134, 824-830 (2014). Together with Simpson et al. (2014), first reported on the putative preventive value of simple skin care in newborns at risk of developing $A D$.

50. Perrett, K. P. \& Peters, R. L. Emollients for prevention of atopic dermatitis in infancy. Lancet 395, 923-924 (2020).

51. Skjerven, H. O. et al. Skin emollient and early complementary feeding to prevent infant atopic dermatitis (PreventADALL): a factorial, multicentre, cluster-randomised trial. Lancet 395, 951-961 (2020).

52. Briot, A. et al. Kallikrein 5 induces atopic dermatitislike lesions through PAR2-mediated thymic stromal lymphopoietin expression in Netherton syndrome. J. Exp. Med. 206, 1135-1147 (2009).

53. Saunders, S. P. et al. Spontaneous atopic dermatitis is mediated by innate immunity, with the secondary lung inflammation of the atopic march requiring adaptive immunity. J. Allergy Clin. Immunol. 137, 482-491 (2016).

54. Chieosilapatham, P. et al. Keratinocytes: innate immune cells in atopic dermatitis. Clin. Exp. Immunol. 204, 296-309 (2021)

55. Han, H., Roan, F. \& Ziegler, S. F. The atopic march: current insights into skin barrier dysfunction and epithelial cell-derived cytokines. Immunol. Rev. 278 116-130 (2017)

56. Haarmann-Stemmann, T., Esser, C. \& Krutmann, J. The Janus-faced role of aryl hydrocarbon receptor signaling in the skin: consequences for prevention and treatment of skin disorders. J. Invest. Dermatol. 135 2572-2576 (2015).

57. Hidaka, T. et al. The aryl hydrocarbon receptor AhR links atopic dermatitis and air pollution via induction of the neurotrophic factor artemin. Nat. Immunol. 18, 64-73 (2017) Important paper reporting on the role of the xenobiotic receptor AhR in sensing environmental factors to induce $A D$ lesions in an animal model.

58. Trikha, P. \& Lee, D. A. The role of AhR in transcriptional regulation of immune cell development and function. Biochim. Biophys. Acta Rev. Cancer 1873, 188335 (2020)

59. van den Bogaard, E. H. et al. Coal tar induces AHRdependent skin barrier repair in atopic dermatitis. J. Clin. Invest. 123, 917-927 (2013)

60. Smith, S. H. et al. Tapinarof Is a natural AhR agonist that resolves skin inflammation in mice and humans. J. Invest. Dermatol. 137, 2110-2119 (2017).

61. Paller, A. S. et al. Efficacy and patient-reported outcomes from a phase $2 \mathrm{~b}$, randomized clinical trial of tapinarof cream for the treatment of adolescents and adults with atopic dermatitis. J. Am. Acad. Dermatol. 84, 632-638 (2020)

62. Peppers, J. et al. A phase 2, randomized dose-finding study of tapinarof (CSK2894512 cream) for the treatment of atopic dermatitis. J. Am. Acad. Dermatol. 80, 89-98 (2019).

First report on the improvement of AD upon topical AhR antagonist treatment.

63. Stein Gold, L., Bhatia, N., Tallman, A. M. \& Rubenstein, D. S. A phase $2 b$, randomized clinical trial of tapinarof cream for the treatment of plaque psoriasis: secondary efficacy and patient-reported outcomes. J. Am. Acad. Dermatol. 84, 624-631 (2020).

64. Hammad, H. \& Lambrecht, B. N. Barrier epithelial cells and the control of type 2 immunity. Immunity 43 29-40 (2015)
65. Menzies-Gow, A. et al. DESTINATION: a phase 3, multicentre, randomized double-blind, placebocontrolled, parallel-group trial to evaluate the longterm safety and tolerability of tezepelumab in adults and adolescents with severe, uncontrolled asthma. Respir. Res. 21, 279 (2020).

66. Mullard, A. Tezepelumab prepares to enter the asthma antibody fray. Nat. Rev. Drug Discov. 20, 91 (2021).

67. Simpson, E. L. et al. Tezepelumab, an anti-thymic stromal lymphopoietin monoclonal antibody, in the treatment of moderate to severe atopic dermatitis: a randomized phase 2 a clinical trial. J. Am. Acad. Dermatol. 80, 1013-1021 (2019)

68. Chen, Y. L. et al. Proof-of-concept clinical trial of etokimab shows a key role for IL-33 in atopic dermatitis pathogenesis. Sci. Transl Med. 11 , eaax2945 (2019)

69. Archer, N. K. et al. Injury, dysbiosis, and filaggrin deficiency drive skin inflammation through keratinocyte IL-1 alpha release. J. Allergy Clin. Immunol. 143, 1426-1443 (2019).

70. Kurzrock, R. et al. Interleukin-1 receptor antagonist levels predict favorable outcome after bermekimab, a first-in-class true human interleukin-1 alpha antibody, in a phase III randomized study of advanced colorectal cancer. Oncoimmunology 8, 1551651 (2019).

71. McDonald, J. J., McMillan, D. C. \& Laird, B. J. A. Targeting IL-1 alpha in cancer cachexia: a narrative review. Curr. Opin. Support. Palliat. Care 12. 453-459 (2018).

72. Gottlieb, A. et al. A phase II open-label study of bermekimab in patients with hidradenitis suppurativa shows resolution of inflammatory lesions and pain. J. Invest. Dermatol. 140, 1538-1545 (2020).

73. Liu, H. et al. Staphylococcus aureus epicutaneous exposure drives skin inflammation via IL-36-mediated T cell responses. Cell Host Microbe 22, 653-666 (2017).

Report on the direct impact of the microbiome on inflammation via the IL-36 pathway.

74. Bachelez, H. et al. Inhibition of the interleukin-36 pathway for the treatment of generalized pustular psoriasis. N. Engl. J. Med. 380, 981-983 (2019).

75. Brunner, P. M. Early immunologic changes during the onset of atopic dermatitis. Ann. Allergy Asthma Immunol. 123, 152-157 (2019).

76. Brunner, P. M. et al. The blood proteomic signature of early-onset pediatric atopic dermatitis shows systemic inflammation and is distinct from adult, longstanding disease. J. Am. Acad. Dermatol. 81, 510-519 (2019).

77. Zhou, L. et al. Age-specific changes in the molecular phenotype of patients with moderate-to-severe atopic dermatitis. J. Allergy Clin. Immunol. 144, 144-156 (2019).

78. Guttman-Yassky, E. et al. GBR 830, an anti-OX40, improves skin gene signatures and clinical scores in patients with atopic dermatitis. J. Allergy Clin. Immunol. 144, 482-493 (2019). First report on the therapeutic potential of a targeted therapy aiming to impact antigen presentation.

79. Nakagawa, H. et al. Safety, tolerability and efficacy of repeated intravenous infusions of KHK4083, a fully human anti-OX40 monoclonal antibody, in Japanese patients with moderate to severe atopic dermatitis. J. Dermatol. Sci. 99, 82-89 (2020).

80. Akdis, C. A. et al. Type 2 immunity in the skin and lungs. Allergy 75, 1582-1605 (2020).

81. Gandhi, N. A. et al. Targeting key proximal drivers of type 2 inflammation in disease. Nat. Rev. Drug Discov. 15, 35-50 (2016).

Key review paper on the targeted therapy aiming to alter the dominant $\mathrm{T}_{\mathrm{H}} 2$ pathways in allergic disorders.

82. Gandhi, N. A., Pirozzi, G. \& Graham, N. M. H. Commonality of the IL-4/IL-13 pathway in atopic diseases. Expert. Rev. Clin. Immunol. 13, 425-437 (2017).

83. Faiz, S. et al. Effectiveness and safety of dupilumab for the treatment of atopic dermatitis in a real-life French multicenter adult cohort. J. Am. Acad. Dermatol. 81 , 143-151 (2019).

84. Abraham, S. et al. Implementation of dupilumab in routine care of atopic eczema. Results from the German national registry TREATgermany. Br. J. Dermatol. 183, 382-384 (2020).

85. Deleuran, M. et al. Dupilumab shows long-term safety and efficacy in patients with moderate to severe atopic dermatitis enrolled in a phase 3 open-label extension study. J. Am. Acad. Dermatol. 82 , 377-388 (2020). 
86. Wang, C., Kraus, C. N., Patel, K. G., Ganesan, A. K. \& Grando, S. A. Real-world experience of dupilumab treatment for atopic dermatitis in adults: a retrospective analysis of patients' records. Int. J. Dermatol. 59, 253-256 (2020).

87. Bao, K. \& Reinhardt, R. L. The differential expression of IL- 4 and IL-13 and its impact on type-2 immunity. Cytokine 75, 25-37 (2015). Important paper explaining the different roles and impacts of IL-4 and IL-13 within the $\mathrm{T}_{\mathrm{H}} 2$ immune response and inflammation.

88. Tsoi, L. C. et al. Atopic dermatitis is an IL-13-dominant disease with greater molecular heterogeneity compared to psoriasis. J. Invest. Dermatol. 139, 1480-1489 (2019).

89. Bieber, T. Interleukin-13: targeting an underestimated cytokine in atopic dermatitis. Allergy 75, 54-62 (2020).

90. Popovic, B. et al. Structural characterisation reveals mechanism of IL-13-neutralising monoclonal antibody tralokinumab as inhibition of binding to IL-13ralpha 1 and IL-13Ralpha2. J. Mol. Biol. 429, 208-219 (2017).

91. May, R. D. \& Fung, M. Strategies targeting the IL-4/ IL-13 axes in disease. Cytokine 75, 89-116 (2015).

92. Wollenberg, A. et al. Tralokinumab for moderateto-severe atopic dermatitis: results from two 52-week, randomized, double-blind, multicentre, placebocontrolled phase III trials (ECZTRA 1 and ECZTRA 2). Br. J. Dermatol. 184, 437-449 (2020).

93. Akinlade, B. et al. Conjunctivitis in dupilumab clinical trials. Br. J. Dermatol. 181, 459-473 (2019)

94. Bansal, A. et al. Conjunctivitis in dupilumab clinical trials for adolescents with atopic dermatitis or asthma. Am. J. Clin. Dermatol. 22, 101-115 (2021).

95. Ultsch, M. et al. Structural basis of signaling blockade by anti-IL-13 antibody lebrikizumab. J. Mol. Biol. 425, 1330-1339 (2013).

96. Guttman-Yassky, E. et al. Efficacy and safety of lebrikizumab, a high-affinity interleukin 13 inhibitor, in adults with moderate to severe atopic dermatitis: a phase $2 \mathrm{~b}$ randomized clinical trial. JAMA Dermatol. 156, 411-420 (2020).

97. Byeon, J. H. et al. Correlation of serum interleukin-31 with pruritus and blood eosinophil markers in children with atopic dermatitis. Allergy Asthma Proc. 41, 59-65 (2020).

98. Kim, H. S. et al. Eosinophil-derived neurotoxin as a biomarker for disease severity and relapse in recalcitrant atopic dermatitis. Ann. Allergy Asthma Immunol. 119, 441-445 (2017).

99. Oldhoff, J. M. et al. Anti-IL-5 recombinant humanized monoclonal antibody (mepolizumab) for the treatment of atopic dermatitis. Allergy 60 693-696 (2005)

100. Lack, G. Update on risk factors for food allergy. J. Allergy Clin. Immunol. 129, 1187-1197 (2012).

101. Tang, T. S., Bieber, T. \& Williams, H. C. Does "autoreactivity" play a role in atopic dermatitis? J. Allergy Clin. Immunol. 129, 1209-1215 (2012). Review paper analysing the evidence for autoimmunity in $A D$

102. Laske, N. \& Niggemann, B. Does the severity of atopic dermatitis correlate with serum IgE levels? Pediatr. Allergy Immunol. 15, 86-88 (2004).

103. Suarez-Farinas, M. et al. Intrinsic atopic dermatitis shows similar TH2 and higher TH1 7 immune activation compared with extrinsic atopic dermatitis. J. Allergy Clin. Immunol. 132, 361-370 (2013)

104. Werfel, T. et al. Exacerbation of atopic dermatitis on grass pollen exposure in an environmental challeng chamber. J. Allergy Clin. Immunol. 136, 96-103 (2015).

Further evidence for a role of IgE-mediated allergy to aeroallergens in $A D$

105. Roerdink, E. M. et al. Association of food allergy and atopic dermatitis exacerbations. Ann. Allergy Asthma Immunol. 116, 334-338 (2016).

106. Novak, N. et al. FceRl engagement of Langerhans cell-like dendritic cells and inflammatory dendritic epidermal cell-like dendritic cells induces chemotactic signals and different T-cell phenotypes in vitro. J. Allergy Clin Immunol 113, 949-957 (2004)

107. Heil, P. M., Maurer, D., Klein, B., Hultsch, T. \& Stingl, G. Omalizumab therapy in atopic dermatitis: depletion of IgE does not improve the clinical course a randomized, placebo-controlled and double blind pilot study. J. Dtsch. Dermatol. Ges. 8, 990-998 (2010).

108. Krathen, R. A. \& Hsu, S. Failure of omalizumab for treatment of severe adult atopic dermatitis J. Am. Acad. Dermatol. 53, 338-340 (2005).
109. Zink, A. et al. Targeting IgE in severe atopic dermatitis with a combination of immunoadsorption and omalizumab. Acta Derm. Venereol. 96, 72-76 (2016).

110. Hotze, M. et al. Increased efficacy of omalizumab in atopic dermatitis patients with wild-type filaggrin status and higher serum levels of phosphatidylcholines. Allergy 69, 132-135 (2014).

111. Lane, J. E., Cheyney, J. M., Lane, T. N., Kent, D. E. $\&$ Cohen, D. J. Treatment of recalcitrant atopic dermatitis with omalizumab. J. Am. Acad. Dermatol. 54, 68-72 (2006).

112. Holm, J. G., Agner, T., Sand, C. \& Thomsen, S. F. Omalizumab for atopic dermatitis: case series and a systematic review of the literature. Int. J. Dermatol. 56, 18-26 (2017)

113. Chan, S. et al. Atopic dermatitis anti-IgE paediatric trial (ADAPT): the role of anti-IgE in severe paediatric eczema: study protocol for a randomised controlled trial. Trials 18, 136 (2017).

114. Chan, S., Cornelius, V., Cro, S., Harper, J. I. \& Lack, C. Treatment effect of omalizumab on severe pediatric atopic dermatitis: the ADAPT randomized clinical trial. JAMA Pediatr. 174, 29-37 (2019).

115. Liour, S. S., Tom, A., Chan, Y. H. \& Chang, T. W. Treating IgE-mediated diseases via targeting IgEexpressing B cells using an anti-CemX antibody. Pediatr. Allergy Immunol. 27, 446-451 (2016) Explains the strategy of depleting IgE-committed $B$ cells by targeting membrane IgE.

116. Nograles, K. E. et al. IL-22-producing "T22" T cells account for upregulated IL-22 in atopic dermatitis despite reduced IL-17-producing TH17 T cells. J. Allergy Clin. Immunol. 123, 1244-1252 (2009).

117. Esaki, H. et al. Early-onset pediatric atopic dermatitis is TH2 but also TH1 7 polarized in skin. J. Allergy Clin. Immunol. 138, 1639-1651 (2016).

118. Niebuhr, M., Scharonow, H., Gathmann, M., Mamerow, D. \& Werfel, T. Staphylococcal exotoxins are strong inducers of IL-22: a potential role in atopic dermatitis. J. Allergy Clin. Immunol. 126, 1176-1183 (2010).

119. Gittler, J. K. et al. Progressive activation of $\mathrm{T}(\mathrm{H}) 2$ $T(H) 22$ cytokines and selective epidermal proteins characterizes acute and chronic atopic dermatitis. J. Allergy Clin. Immunol. 130, 1344-1354 (2012).

120. Gutowska-Owsiak, D., Schaupp, A. L., Salimi, M. Taylor, S. \& Ogg, G. S. Interleukin-22 downregulates filaggrin expression and affects expression of profilaggrin processing enzymes. Br. J. Dermatol. 165, 492-498 (2011).

121. Eyerich S et al. Th22 cells represent a distinct human $\mathrm{T}$ cell subset involved in epidermal immunity and remodeling. J. Clin. Invest. 119, 3573-3585 (2009).

122. Guttman-Yassky, E. et al. Efficacy and safety of fezakinumab (an IL-22 monoclonal antibody) in adults with moderate-to-severe atopic dermatitis inadequately controlled by conventional treatments: a randomized, double-blind, phase 2a trial. J. Am. Acad. Dermatol. 78, 872-881 (2018)

123. Noda, S. et al. The Asian atopic dermatitis phenotype combines features of atopic dermatitis and psoriasis with increased TH1 7 polarization. J. Allergy Clin. Immunol. 136, 1254-1264 (2015).

The first report on $T_{H} 17$ immune polarization in Asian patients, questioning the dogma of the $\mathrm{T}_{\mathrm{H}} 2$ immune dominance in $A D$.

124. Czarnowicki, T. et al. Evolution of pathologic T-cell subsets in patients with atopic dermatitis from infancy to adulthood. J. Allergy Clin. Immunol. 145, 215-228 (2020).

125. Renert-Yuval, Y. et al. The molecular features of normal and atopic dermatitis skin in infants, children, adolescents and adults. J. Allergy Clin. Immunol. 148 148-163 (2021)

126. Ungar, B. et al. Phase 2 randomized, double-blind study of IL-1 7 targeting with secukinumab in atopic dermatitis. J. Allergy Clin. Immunol. 147, 394-397 (2021).

127. Grewe, S. R., Chan, S. C. \& Hanifin, J. M. Elevated leukocyte cyclic AMP-phosphodiesterase in atopic disease: a possible mechanism for cyclic AMP-agonist hyporesponsiveness. J. Allergy Clin. Immunol. 70 452-457 (1982)

128. Li, H., Zuo, J. \& Tang, W. Phosphodiesterase-4 inhibitors for the treatment of inflammatory diseases. Front. Pharmacol. 9, 1048 (2018).

129. Samrao, A., Berry, T. M., Goreshi, R. \& Simpson, E. L. A pilot study of an oral phosphodiesterase inhibitor (apremilast) for atopic dermatitis in adults. Arch. Dermatol. 148, 890-897 (2012).
130. Volf, E. M., Au, S. C., Dumont, N., Scheinman, P. \& Gottlieb, A. B. A phase 2, open-label, investigatorinitiated study to evaluate the safety and efficacy of apremilast in subjects with recalcitrant allergic contact or atopic dermatitis. J. Drugs Dermatol. 11, 341-346 (2012).

131. Simpson, E. L. et al. A phase 2 randomized trial of apremilast in patients with atopic dermatitis. J. Invest Dermatol. 139, 1063-1072 (2019).

132. Furue, M. et al. Safety and efficacy of topical E6005, a phosphodiesterase 4 inhibitor, in Japanese adult patients with atopic dermatitis: results of a randomized, vehicle-controlled, multicenter clinical trial. J. Dermatol. 41, 577-585 (2014)

133. Nemoto, O. et al. Effect of topical phosphodiesterase 4 inhibitor E6005 on Japanese children with atopic dermatitis: results from a randomized, vehiclecontrolled exploratory trial. J. Dermatol. 43 881-887 (2016)

134. Hanifin, J. M. et al. OPA-15406, a novel, topical, nonsteroidal, selective phosphodiesterase-4 (PDE4) inhibitor in the treatment of adult and adolescent patients with mild to moderate atopic dermatitis (AD): a phase-Il randomized, double-blind, placebo controlled study. J. Am. Acad. Dermatol. 75 297-305 (2016).

135. Saeki, H., Baba, N., Oshiden, K., Abe, Y. $\delta$ Tsubouchi, H. Phase 2, randomized, double-blind placebo-controlled, 4-week study to evaluate the safety and efficacy of OPA- 15406 (difamilast), a new topical selective phosphodiesterase type-4 inhibitor in Japanese pediatric patients aged 2-14 years with atopic dermatitis. J. Dermatol. 47, 17-24 (2020)

136. Felding, J. et al. Discovery and early clinical development of2-\{6-[2-(3,5-dichloro-4-pyridyl)acetyl]2,3-dimethoxyphenoxy\}- $N$-propylacetamide (LEO 29102), a soft-drug inhibitor of phosphodiesterase 4 for topical treatment of atopic dermatitis. J. Med. Chem. 57, 5893-5903 (2014).

137. Cataldi, M., Borriello, F., Granata, F., Annunziato, L. \& Marone, G. Histamine receptors and antihistamines: from discovery to clinical applications. Chem. Immunol. Allergy 100, 214-226 (2014).

138. Lazewska, D. \& Kiec-Kononowicz, K. Azines as histamine $\mathrm{H} 4$ receptor antagonists. Front. Biosci. 4, 967-987 (2012).

139. Fang, Q. et al. Histamine-4 receptor antagonist ameliorates Parkinson-like pathology in the striatum. Brain Behav. Immun. 92, 127-138 (2021).

140. Dettori, I. et al. A selective histamine $\mathrm{H} 4$ receptor antagonist, JNJ7777120, is protective in a rat model of transient cerebral ischemia. Front. Pharmacol. 9 1231 (2018).

141. Cowden, J. M., Riley, J. P., Ma, J. Y., Thurmond, R. L. \& Dunford, P. J. Histamine $\mathrm{H} 4$ receptor antagonism diminishes existing airway inflammation and dysfunction via modulation of Th2 cytokines. Respir. Res. 11, 86 (2010).

142. Somma, T. et al. A selective antagonist of histamine $\mathrm{H}(4)$ receptors prevents antigen-induced airway inflammation and bronchoconstriction in guinea pigs: involvement of lipocortin-1. Br. J. Pharmacol. 170, 200-213 (2013)

143. Rossbach, K. et al. Histamine H4 receptor knockout mice display reduced inflammation in a chronic model of atopic dermatitis. Allergy 71, 189-197 (2016).

144. Gutzmer, R. et al. The histamine $\mathrm{H} 4$ receptor is functionally expressed on $\mathrm{T}(\mathrm{H}) 2$ cells. J. Allergy Clin. Immunol. 123, 619-625 (2009).

145. Gutzmer, R. et al. Pathogenetic and therapeutic implications of the histamine $\mathrm{H} 4$ receptor in inflammatory skin diseases and pruritus. Front. Biosci. 3, 985-994 (2011).

146. Han, S. H. et al. Preliminary study of histamine H4 receptor expressed on human CD4(+) T cells and its mmunomodulatory potency in the IL-17 pathway of psoriasis. J. Dermatol. Sci. 88, 29-35 (2017).

147. Kochling, $\mathrm{H}$. et al. Combined treatment with $\mathrm{H} 1$ and $\mathrm{H} 4$ receptor antagonists reduces inflammation in a mouse model of atopic dermatitis. J. Dermatol. Sci. 87, 130-137 (2017).

148. Werfel, T., Asher, A., Tsianakas, A., Gupta, B. \& Sarmiento, R. A phase 2a proof of concept clinical trial to evaluate ZPL-3893787 (ZPL-389), a potent, oral histamine $\mathrm{H}-4$ receptor antagonist for the treatment of moderate to severe atopic dermatitis (AD) in adults. Allergy 71, 95-95 (2016).

149. Castan, L., Magnan, A. \& Bouchaud, G. Chemokine receptors in allergic diseases. Allergy 72, 682-690 (2017). 
150. Abboud, D. \& Hanson, J. Chemokine neutralization as an innovative therapeutic strategy for atopic dermatitis. Drug Discov. Today 22, 702-711 (2017).

151. Marone, G. et al. Prostaglandin D2 receptor antagonists in allergic disorders: safety, efficacy, and future perspectives. Expert Opin. Investig. Drugs 28 73-84 (2019) Interesting review on the pharmacology of PGD2 receptor antagonists.

152. Cosmi, L. et al. CRTH2 is the most reliable marker for the detection of circulating human type 2Th and type $2 \mathrm{~T}$ cytotoxic cells in health and disease. Eur. J. Immunol. 30, 2972-2979 (2000).

153. Iwasaki, M. et al. Association of a new-type prostaglandin D2 receptor CRTH2 with circulating T helper 2 cells in patients with atopic dermatitis. J. Invest. Dermatol. 119, 609-616 (2002).

154. Boehme, S. A. et al. A small molecule CRTH2 antagonist inhibits FITC-induced allergic cutaneous inflammation. Int. Immunol. 21, 81-93 (2008).

155. He, R. et al. The prostaglandin $\mathrm{D}(2)$ receptor CRTH2 is important for allergic skin inflammation after epicutaneous antigen challenge. J. Allergy Clin. Immunol. 126, 784-790 (2010).

156. Kataoka, Y. Thymus and activation-regulated chemokine as a clinical biomarker in atopic dermatitis. J. Dermatol. 41, 221-229 (2014).

157. Renert-Yuval, Y. et al. Biomarkers in atopic dermatitis-a review on behalf of the International Eczema Council. J. Allergy Clin. Immunol. 147, 1174-1190 (2021)

State of the art review paper in the field of biomarker discovery in $\mathrm{AD}$

158. Alessenko, A. V. \& Albi, E. Exploring sphingolipid implications in neurodegeneration. Front. Neurol. 11, 437 (2020).

159. Hsu, S. C. et al. Circulating sphingosine-1-phosphate as a prognostic biomarker for community-acquired pneumonia. PLOS ONE 14, e0216963 (2019).

160. Checa, A. et al. Circulating levels of sphingosine-1 phosphate are elevated in severe, but not mild psoriasis and are unresponsive to anti-TNF-alpha treatment. Sci. Rep. 5, 12017 (2015).

161. Kim, S. H. et al. Ceramide/sphingosine-1-phosphate imbalance is associated with distinct inflammatory phenotypes of uncontrolled asthma. Allergy 75 1991-2004 (2020).

162. Sakai, T. et al. Serum sphingosine-1-phosphate is elevated in atopic dermatitis and associated with the severity and inflammation. Allergy https://doi.org/ 10.1111/all.14826 (2021)

163. Rivera, J., Proia, R. L. \& Olivera, A. The alliance of sphingosine-1-phosphate and its receptors in immunity. Nat. Rev. Immunol. 8, 753-763 (2008)

164. Bock, S., Pfalzgraff, A. \& Weindl, G. Sphingosine 1-phospate differentially modulates maturation and function of human Langerhans-like cells. J. Dermatol. Sci. 82, 9-17 (2016).

165. Japtok, L. et al. Sphingosine 1-phosphate modulates antigen capture by murine Langerhans cells via the S1P2 receptor subtype. PLoS ONE 7, e49427 (2012).

166. Blaho, V. A. \& Hla, T. An update on the biology of sphingosine 1-phosphate receptors. J. Lipid Res. 55 1596-1608 (2014).

167. Chun, J., Kihara, Y., Jonnalagadda, D. \& Blaho, V. A Fingolimod: lessons learned and new opportunities for treating multiple sclerosis and other disorders. Annu. Rev. Pharmacol. Toxicol. 59, 149-170 (2019).

168. Gajofatto, A. \& Turatti, M. Siponimod to treat secondary progressive multiple sclerosis. Drugs Today 56, 37-46 (2020).

169. Tsuji, T. et al. Therapeutic approach to mite-induced intractable dermatitis using novel immunomodulato FTY720 ointment (fingolimod) in NC/Nga mice. Allergol. Int. 65, 172-179 (2016)

170. Schaper, K. et al. Sphingosine-1-phosphate exhibits anti-proliferative and anti-inflammatory effects in mouse models of psoriasis. J. Dermatol. Sci. 71 29-36 (2013).

171. Park, S. J. \& Im, D. S. Blockage of sphingosine-1phosphate receptor 2 attenuates 2,4dinitrochlorobenzene-induced atopic dermatitis in mice. Acta Pharmacol. Sin. 41, 1487-1496 (2020)

172. Bryan, A. M. $\&$ Del Poeta, M. Sphingosine-1phosphate receptors and innate immunity. Cell Microbiol. 20, e12836 (2018). Key review on the role of S1P in the mechanisms of innate immunity

173. Jeon, S. et al. Inhibition of sphingosine 1-phosphate lyase activates human keratinocyte differentiation and attenuates psoriasis in mice. J. Lipid Res. 61, 20-32 (2020).
174. Igawa, S. et al. Sphingosine 1-phosphate receptor 2 is central to maintaining epidermal barrier homeostasis. J. Invest. Dermatol. 141, 1188-1197 (2021).

175. Igawa, S. et al. Human keratinocytes use sphingosine 1-phosphate and its receptors to communicate Staphylococcus aureus invasion and activate host defense. J. Invest. Dermatol. 139, 1743-1752 (2019).

176. Jeong, S. K. et al. Sphingosine kinase 1 activation enhances epidermal innate immunity through sphingosine-1-phosphate stimulation of cathelicidin production. J. Dermatol. Sci. 79, 229-234 (2015).

177. Arlt, O. et al. Sphingosine-1-phosphate modulates dendritic cell function: focus on non-migratory effects in vitro and in vivo. Cell Physiol. Biochem. 34, 27-44 (2014).

178. Xiong, M. et al. The sphingosine 1-phosphate receptor agonist FTY720 interfered the distribution of dendritic cell and induced the maternal-fetal immune tolerance. J. Cell. Biochem. https://doi.org/10.1002/jcb.27501 (2018).

179. Karuppuchamy, T. et al. Sphingosine-1-phosphate receptor-1 (S1P1) is expressed by lymphocytes, dendritic cells, and endothelium and modulated during inflammatory bowel disease. Mucosal Immunol. 10, 162-171 (2017).

180. Oetjen, L. K. et al. Sensory neurons co-opt classical immune signaling pathways to mediate chronic Itch. Cell 171, 217-228 (2017). Key paper on how immune mediators interact with sensory neurons to induce itching sensation

181. Erickson, S. Heul, A. V. \& Kim, B. S. New and emerging treatments for inflammatory itch. Ann. Allergy Asthma Immunol. 126, 13-20 (2021).

182. Yang, T. B. \& Kim, B. S. Pruritus in allergy and immunology. J. Allergy Clin. Immunol. 144, 353-360 (2019).

183. Simpson, E. L. et al. Two phase 3 trials of dupilumab versus placebo in atopic dermatitis. N. Engl. J. Med. 375, 2335-2348 (2016)

Reports on the pivotal studies that have led to the approval of dupilumab as the first-in-class biologic for the therapy of $A D$.

184. Furue, M., Yamamura, K., Kido-Nakahara, M., Nakahara, T. \& Fukui, Y. Emerging role of interleukin-31 and interleukin-31 receptor in pruritus in atopic dermatitis. Allergy 73, 29-36 (2018).

185. Raap, U. et al. Correlation of IL-31 serum levels with severity of atopic dermatitis. J. Allergy Clin. Immunol. 122, 421-423 (2008)

186. Jones, S. A. \& Jenkins, B. J. Recent insights into targeting the IL- 6 cytokine family in inflammatory diseases and cancer. Nat. Rev. Immunol. 18 773-789 (2018).

187. Hermanns, H. M. Oncostatin M and interleukin-31: cytokines, receptors, signal transduction and physiology. Cytokine Growth Factor. Rev. 26 545-558 (2015)

188. Nakashima, C., Otsuka, A. \& Kabashima, K. Interleukin-31 and interleukin-31 receptor: new therapeutic targets for atopic dermatitis. Exp. Dermatol. 27, 327-331 (2018).

189. Ruzicka, T. et al. Anti-interleukin-31 receptor a antibody for atopic dermatitis. N. Engl. J. Med. 376 826-835 (2017)

190. Kabashima, K. et al. Nemolizumab in patients with moderate-to-severe atopic dermatitis: randomized, phase II, long-term extension study. J. Allergy Clin. Immunol. 142, 1121-1130 (2018).

191. Silverberg, J. I. et al. Phase 2B randomized study of nemolizumab in adults with moderate-to-sever atopic dermatitis and severe pruritus. J. Allergy Clin. Immunol. 145, 173-182 (2020).

192. Kabashima, K., Matsumura, T., Komazaki, H. \& Kawashima, M., Nemolizumab-JP01 Study Group. Trial of nemolizumab and topical agents for atopic dermatitis with pruritus. N. Engl. J. Med. 383, $141-150$ (2020)

193. Stander, S. et al. Trial of nemolizumab in moderateto-severe prurigo nodularis. N. Engl. J. Med. $\mathbf{3 8 2}$ 706-716 (2020)

Report on the efficacy of the anti-IL-31 biologic nemolizumab in prurigo nodularis.

194. Mihak, Z. et al. KPL-716, anti-Oncostatin M receptor beta antibody, reduced pruritus in atopic dermatitis [abstract 560]. J. Invest. Dermatol. 139 (Suppl.), S96 (2019).

195. Steinhoff, M. S., von Mentzer, B., Geppetti, P. Pothoulakis, C. \& Bunnett, N. W. Tachykinins and their receptors: contributions to physiological control and the mechanisms of disease. Physiol. Rev. 94 265-301 (2014)
196. Douglas, S. D. \& Leeman, S. E. Neurokinin-1 receptor: functional significance in the immune system in reference to selected infections and inflammation Ann. NY Acad. Sci. 1217, 83-95 (2011).

197. Azimi, E. et al. Dual action of neurokinin-1 antagonists on Mas-related GPCRs. JCl Insight 1, e89362 (2016).

198. Azimi, E. et al. Substance P activates Mas-related C protein-coupled receptors to induce itch. J. Allergy Clin. Immunol. 140, 447-453 (2017).

199. Pincelli, C et al. Neuropeptides in skin from patients with atopic dermatitis: an immunohistochemical study. Br. J. Dermatol. 122, 745-750 (1990).

200. Tobin, D. et al. Increased number of immunoreactive nerve fibers in atopic dermatitis. J. Allergy Clin. Immunol. 90, 613-622 (1992).

201. Jarvikallio, A., Harvima, I. T. \& Naukkarinen, A. Mast cells, nerves and neuropeptides in atopic dermatitis and nummular eczema. Arch. Dermatol. Res. 295, 2-7 (2003).

202. Nattkemper, L. A et al. The genetics of chronic itch: gene expression in the skin of patients with atopic dermatitis and psoriasis with severe itch. J. Invest. Dermatol. 138, 1311-1317 (2018). One of the first analysis of similarities and differences in itch in the two most common inflammatory skin disorders.

203. Stander, S. \& Luger, T. A. NK-1 antagonists and itch Handb. Exp. Pharmacol. 226, 237-255 (2015).

204. Zeidler, C. \& Stander, S. The pathogenesis of prurigo nodularis-'super-itch' in exploration. Eur. J. Pain. 20 37-40 (2016)

205. Stander, S. et al. Serlopitant reduced pruritus in patients with prurigo nodularis in a phase 2 , randomized, placebo-controlled trial. J. Am. Acad. Dermatol. 80, 1395-1402 (2019).

206. Welsh, S. E. et al. Neurokinin-1 receptor antagonist tradipitant has mixed effects on itch in atopic dermatitis: results from EPIONE, a randomized clinical trial. J. Eur. Acad. Dermatol. Venereol. 35, e338-e340 (2021).

207. Dicpinigaitis, P. V., McGarvey, L. P. \& Canning B. J. P2X3-receptor antagonists as potential antitussives: summary of current clinical trials in chronic cough. Lung 198, 609-616 (2020)

208. Inoue, K. \& Tsuda, M. Nociceptive signaling mediated by $\mathrm{P} 2 \mathrm{X} 3, \mathrm{P} 2 \mathrm{X} 4$ and $\mathrm{P} 2 \mathrm{X} 7$ receptors. Biochem. Pharmacol. 187, 114309 (2020).

209. Ford, A. P. \& Undem, B. J. The therapeutic promise of ATP antagonism at $\mathrm{P} 2 \mathrm{X} 3$ receptors in respiratory and urological disorders. Front. Cell Neurosci. 7, 267v (2013).

210. Stander, S., Spellman, M. C., Kwon, P. \& Yosipovitch, G. The NK 1 receptor antagonist serlopitant for treatment of chronic pruritus. Expert Opin. Investig. Drugs 28, 659-666 (2019).

211. Hashimoto, T. et al. Itch intensity in prurigo nodularis is closely related to dermal interleukin-31, oncostatin $\mathrm{M}, \mathrm{IL}-31$ receptor alpha and oncostatin $\mathrm{M}$ receptor beta. Exp. Dermatol. 30, 804-810 (2021).

212. Fourzali, K., Golpanian, R. S. \& Yosipovitch, G. Emerging drugs for the treatment of chronic pruritic diseases. Expert Opin. Emerg. Drugs 25, 273-284 (2020).

213. Villarino, A. V., Kanno, Y. \& O’Shea, J. J. Mechanisms and consequences of Jak-STAT signaling in the immune system. Nat. Immunol. 18, 374-384 (2017). Detailed review on the significance of the JAK-STAT pathway and how to interact with it.

214. Spangler, J. B., Moraga, I., Mendoza, J. L. \& Garcia, K. C. Insights into cytokine-receptor interactions from cytokine engineering. Annu. Rev. Immunol. 33, 139-167 (2015).

215. Schwartz, D. M., Bonelli, M., Gadina, M. $\delta$ O'Shea, J. J. Type I/II cytokines, JAKs, and new strategies for treating autoimmune diseases. Nat. Rev. Rheumatol. 12, 25-36 (2016).

Key review on the link between cytokine receptors and the JAK pathways in autoimmune disorders.

216. Villarino, A. V., Gadina, M., O'Shea, J. J. \& Kanno, Y. SnapShot: Jak-STAT signaling II. Cell 181 1696-1696 (2020).

217. Walz, L. et al. JAK-inhibitor and type I interferon ability to produce favorable clinical outcomes in COVID-19 patients: a systematic review and metaanalysis. BMC Infect. Dis. 21, 47 (2021).

218. Uppal, S. K., Kearns, D. G., Chat, V. S. \& Wu, J. J. Ruxolitinib cream for the treatment of vitiligo. Lancet 396, 1735-1736 (2020)

219. Cotter, D. G., Schairer, D. \& Eichenfield, L. Emerging therapies for atopic dermatitis: JAK inhibitors. J. Am. Acad. Dermatol. 78, S53-S62 (2018). 
220. He, H. \& Guttman-Yassky, E. JAK inhibitors for atopic dermatitis: an update. Am. J. Clin. Dermatol. 20 181-192 (2019)

221. Amano, W. et al. The Janus kinase inhibitor JTE-052 improves skin barrier function through suppressing signal transducer and activator of transcription 3 signaling. J. Allergy Clin. Immunol. 136, 667-677 (2015)

222. Tanimoto, A. et al. Pharmacological properties of JTE-052: a novel potent JAK inhibitor that suppresses various inflammatory responses in vitro and in vivo. Inflamm. Res. 64, 41-51 (2015).

223. Yamamoto, Y. et al. Janus kinase inhibitor delgocitinib suppresses pruritus and nerve elongation in an atopic dermatitis murine model. J. Dermatol. Sci. 97 , 161-164 (2020)

224. Nakagawa, H. et al. Delgocitinib ointment, a topical Janus kinase inhibitor, in adult patients with moderate to severe atopic dermatitis: a phase 3, randomized, double-blind, vehicle-controlled study and an open-label, long-term extension study. J. Am. Acad. Dermatol 82, 823-831 (2020).

225. Nakagawa, H. et al. Long-term safety and efficacy of delgocitinib ointment, a topical Janus kinase inhibitor in adult patients with atopic dermatitis. J. Dermatol. 47, 114-120 (2020)

226. Dhillon, S. Delgocitinib: first approval. Drugs $\mathbf{8 0}$, 609-615 (2020)

227. Worm, M. et al. Efficacy and safety of topical delgocitinib in patients with chronic hand eczema: data from a randomized, double-blind, vehiclecontrolled phase Ila study. Br. J. Dermatol. 182, 1103-1110 (2020)

228. Guo, A. et al. Dual SYK/JAK inhibition overcomes ibrutinib resistance in chronic lymphocytic leukemia cerdulatinib, but not ibrutinib, induces apoptosis of tumor cells protected by the microenvironment. Oncotarget 8, 12953-12967 (2017).

229. Bieber, T. et al. Human epidermal Langerhans cells express the high affinity receptor for immunoglobulin $\mathrm{E}$ (Fc epsilon RI). J. Exp. Med. 175, 1285-1290 (1992).

230. Jurgens, M., Wollenberg, A., Hanau, D., de la Salle, H. $\&$ Bieber, T. Activation of human epidermal Langerhans cells by engagement of the high affinity receptor for IgE, Fc epsilon RI. J. Immunol. 155, 5184-5189 (1995).

231. Klaeschen, A. S. et al. JAK1/2 inhibition impairs the development and function of inflammatory dendritic epidermal cells in atopic dermatitis. J. Allergy Clin. Immunol. 147, 2202-2212.e8 (2020).

232. Piscitelli, S. C. et al. A Phase $1 \mathrm{~b}$, randomized, singlecenter trial of topical cerdulatinib (DMVT-502) in patients with mild-to-moderate atopic dermatitis. J. Invest. Dermatol. 141, 1847-1851 (2021).

233. Kim, B. S. et al. Treatment of atopic dermatitis with ruxolitinib cream (JAK1/JAK2 inhibitor) or triamcinolone cream. J. Allergy Clin. Immunol. 145 572-582 (2020)

234. Klaeschen, A. S., Wolf, D., Brossart, P., Bieber, T. \& Wenzel, J. JAK inhibitor ruxolitinib inhibits the expression of cytokines characteristic of cutaneous lupus erythematosus. Exp. Dermatol. 26, 728-730 (2017).

235. Simpson, E. L. et al. Baricitinib in patients with moderate-to-severe atopic dermatitis and inadequate response to topical corticosteroids: results from two randomised monotherapy phase 3 trials. Br. J. Dermatol. 183, 242-255 (2020).

236. Bieber, T. et al. Pooled safety analysis of baricitinib in adult patients with atopic dermatitis from 8 randomized clinical trials. J. Eur. Acad. Dermatol. Venereol. 35, 476-485 (2020)

237. Reich, K. et al. Safety and efficacy of upadacitinib in combination with topical corticosteroids in adolescents and adults with moderate-to-severe atopic dermatitis (AD Up): results from a randomised, double-blind, placebo-controlled, phase 3 trial. Lancet 397, 2169-2181 (2021).

238. Simpson, E. L. et al. Efficacy and safety of abrocitinib in adults and adolescents with moderate-to-sever atopic dermatitis (JADE MONO-1): a multicentre, double-blind, randomised, placebo-controlled, phase 3 trial. Lancet 396, 255-266 (2020). Report on a pivotal study showing the good results obtained with the JAK1 inhibitor abrocitinib in AD.
239. Peters, E. M. et al. Nerve growth factor partially recovers inflamed skin from stress-induced worsening in allergic inflammation. J. Invest. Dermatol. 131 735-743 (2011)

240. Ghaderpour, A., Kim, Y.-H., Lee, H.-C. \& Seong, S.-Y. HY209 ameliorates atopic dermatitis through NF-KB and P38 inhibition. J. Immunol. 204 (Suppl. 1), 147.37 (2020).

241. Schmuth, M., Moosbrugger-Martinz, V., Blunder, S. \& Dubrac, S. Role of PPAR, LXR, and PXR in epidermal homeostasis and inflammation. Biochim. Biophys. Acta 1841, 463-473 (2014).

242. Hashimoto, S., Takanari, H., Compe, E. \& Egly, J. M. Dysregulation of LXR responsive genes contribute to ichthyosis in trichothiodystrophy. J. Dermatol. Sci. 97. 201-207 (2020)

243. Agnihotri, G. \& Lio, P. A. Revisiting therapies for atopic dermatitis that failed clinical trials. Clin. Drug Investig. 40, 421-431 (2020)

244. Bieber, T., Cork, M. \& Reitamo, S. Atopic dermatitis: a candidate for disease-modifying strategy. Allergy 67, 969-975 (2012)

245. Bieber, T. et al. Unraveling the complexity of atopic dermatitis: the CK-CARE approach towards precision medicine. Allergy 11, 2936-2938 (2020).

246. Bieber, T. Atopic dermatitis 2.0: from the clinical phenotype to the molecular taxonomy and stratified medicine. Allergy 67, 1475-1482 (2012).

247. Czarnowicki, T., He, H., Krueger, J. G. \& Guttman-Yassky, E. Atopic dermatitis endotypes and implications for targeted therapeutics. J. Allergy Clin. Immunol. 143, 1-11 (2019).

248. Bieber, T. et al. Clinical phenotypes and endophenotypes of atopic dermatitis: where are we, and where should we go? J. Allergy Clin. Immunol. 139, S58-S64 (2017).

249. Muraro, A et al. Precision medicine in patients with allergic diseases: airway diseases and atopic dermatitis-PRACTALL document of the European Academy of Allergy and Clinical Immunology and the American Academy of Allergy, Asthma \& Immunology. J. Allergy Clin. Immunol. 137, 1347-1358 (2016).

250. Iwamoto, K. et al. Langerhans and inflammatory dendritic epidermal cells in atopic dermatitis are tolerized toward TLR2 activation. Allergy 73 2205-2213 (2018)

The first report that epidermal DCs isolated from AD skin are tolerant to $S$. aureus-derived signals.

251. Nakatsuji, T. et al. Staphylococcus aureus exploits epidermal barrier defects in atopic dermatitis to trigger cytokine expression. J. Invest. Dermatol. 136, 2192-2200 (2016).

252. Irvine, A. D., McLean, W. H. \& Leung, D. Y. Filaggrin mutations associated with skin and allergic diseases. N. Engl. J. Med. 365, 1315-1327 (2011).

253. Howell, M. D. et al. Cytokine modulation of atopic dermatitis filaggrin skin expression. J. Allergy Clin. Immunol. 120, 150-155 (2007). Shows how the inflammatory reaction impacts on the function of the epidermal barrier in AD.

254. Kim, B. E., Leung, D. Y., Boguniewicz, M. $\&$ Howell, M. D. Loricrin and involucrin expression is down-regulated by Th2 cytokines through STAT- 6 . Clin. Immunol. 126, 332-337 (2008)

255. Howell, M. D. et al. Th2 cytokines act on S100/A11 to downregulate keratinocyte differentiation. J. Invest. Dermatol. 128, 2248-2258 (2008).

256. Berdyshev, E. et al. Lipid abnormalities in atopic skin are driven by type 2 cytokines. JCI Insight 3, e98006 (2018).

257. Valenta, R. et al. Immunoglobulin E response to human proteins in atopic patients. J. Invest. Dermatol. 107, 203-208 (1996)

258. Schmitt, J. et al. The Harmonising Outcome Measures for Eczema (HOME) statement to assess clinical signs of atopic eczema in trials. J. Allergy Clin. Immunol. 134, 800-807 (2014).

259. Chalmers, J. R et al. Report from the fourth international consensus meeting to harmonize core outcome measures for atopic eczema/dermatitis clinica trials (HOME initiative). Br. J. Dermatol. 175, 69-79 (2016).

260. Langan, S. M. et al. Measuring long-term disease control in patients with atopic dermatitis: a validation study of well-controlled weeks. J. Allergy Clin. Immunol. 140, 1580-1586 (2017).
261. Thomas, K. S. et al. Recommended core outcome instruments for health-related quality of life, long-term control and itch intensity in atopic eczema trials: results of the HOME VII consensus meeting. Br. J. Dermatol. https://doi.org/10.1111/bjd. 19673 (2021).

262. Charman, C. R., Venn, A. J. \& Williams, H. C. The patient-oriented eczema measure: development and initial validation of a new tool for measuring atopic eczema severity from the patients' perspective. Arch. Dermatol. 140, 1513-1519 (2004).

\section{Acknowledgements}

This work was supported by the Christine Kühne-Center for Allergy Research and Education (CK-CARE).

\section{Competing interests}

T.B. was speaker and/or consultant and/or Investigator for AbbVie, Allmiral, AnaptysBio, Arena, Asana Biosciences, Bayer Health, BioVerSys, Böhringer-Ingelheim, Bristol Myers Squibb, Domain Therapeutics, Galapagos/MorphoSys, Galderma, Glenmark, GSK, Incyte, IOVIA, Janssen, Kirin, Kymab, LEO Pharma, LG Chem, Lilly, L'Oréal, MenloTx, Novartis, Vifor Pharma, Pfizer, Pierre Fabre, Sanofi/Regeneron, UCB. T.B. is founder of the non-profit biotech company Davos Biosciences within the International Kühne Foundation.

\section{Publisher's note}

Springer Nature remains neutral with regard to jurisdictional claims in published maps and institutional affiliations.

\section{RELATED LINKS}

Form 8-K RAPT Therapeutics: https://sec.report/Document/ 0001193125-20-004266

Press bulletin: https://www.kymab.com/media/uploads/files/ 2020-08_Kymab_PR_Completion_KY1005_Phase_2a_-_vFINAL GywxrP5.pdf

Press release from Anaptysbio: Anaptysbio reports etokimab atlas phase $2 \mathrm{~b}$ clinical trial in moderate-to-severe atopic dermatitis fails to meet primary end point:

https://ir.anaptysbio.com/news-releases/news-release-details/ anaptysbio-reports-etokimab-atlas-phase-2b-clinical-trial/

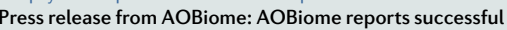
clinical trials (phase $2 a$ in adults and phase $1 b$ in paediatrics) in pruritus (itch) associated with atopic dermatitis: initiates phase $2 \mathrm{~b}$ clinical trial in adults: https://www.aobiome.com/ press/press-releases/

Press release from Arena pharmaceuticals: Arena Pharmaceuticals advancing etrasimod into phase 3 program in atopic dermatitis $(A D)$, reports compelling topline results from phase $2 \mathrm{~b}$ ADVISE trial: https://invest. arenapharm.com/ news-releases/news-release-details/arena-pharmaceuticalsadvancing-etrasimod-phase-3-program-atopic

Press release from Asan Pharmaceuticals: ASLAN Pharmaceuticals announces positive interim data from the multiple ascending dose study of ASLANO04 in atopic dermatitis: http://www.globenewswire.com/fr/news-release/ 2021/03/01/2184010/0/en/ASLAN-PharmaceuticalsAnnounces-Positive-Interim-Data-From-the-MultipleAscending-Dose-Study-of-ASLAN004-in-Atopic-Dermatitis. html

Press release from Forte Bioscience: Forte Biosciences, Inc. announces first patient dosed in the clinical trial of FB-401 for the treatment of children and adults with atopic dermatitis: https://www.fortebiorx.com/investor-relations/ news/news-details/2020/Forte-Biosciences-Inc.-AnnouncesFirst-Patient-Dosed-in-the-Clinical-Trial-of-FB-401-for-theTreatment-of-Children-and-Adults-With-Atopic-Dermatitis/ default.aspx

Press release from Kymab: Kymab announces positive phase 2a results for KY1005 in moderate to severe atopic dermatitis: https://www.kymab.com/media/uploads/ files/2020-08_Kymab_PR_Completion_KY1005_Phase 2a_-_vFINAL_GywxrP5.pdf

Press release from Otsuka: Otsuka announces top-line results from two phase 3 studies in Japan for atopic dermatitis drug candidate difamilast (OPA-15406): https://www.otsuka.co.jp/en/company/newsreleases/2020/ 20200326_1.html

Press release from RAPT Therapeutics: RAPT Therapeutics completes enrolment in phase $1 \mathrm{~b}$ trial of RPT193 in atopic dermatitis: https://rapt.com/news/rapt-therapeuticscompletes-enrolment-in-phase-1b-trial-of-rpt193-inatopic-dermatitis/

(c) Springer Nature Limited 2021 